\title{
An Improved Fruit Fly Optimization Algorithm Inspired from Cell Communication Mechanism
}

\author{
Chuncai Xiao,,$^{1,2}$ Kuangrong Hao, ${ }^{1,2}$ and Yongsheng Ding ${ }^{1,2}$ \\ ${ }^{1}$ Engineering Research Center of Digitized Textile \& Apparel Technology, Ministry of Education, Shanghai 201620, China \\ ${ }^{2}$ College of Information Sciences and Technology, Donghua University, Shanghai 201620, China \\ Correspondence should be addressed to Kuangrong Hao; krhao@dhu.edu.cn and Yongsheng Ding; ysding@dhu.edu.cn
}

Received 4 September 2014; Revised 14 December 2014; Accepted 15 December 2014

Academic Editor: Bo Shen

Copyright (C) 2015 Chuncai Xiao et al. This is an open access article distributed under the Creative Commons Attribution License, which permits unrestricted use, distribution, and reproduction in any medium, provided the original work is properly cited.

Fruit fly optimization algorithm (FOA) invented recently is a new swarm intelligence method based on fruit fly's foraging behaviors and has been shown to be competitive with existing evolutionary algorithms, such as particle swarm optimization (PSO) algorithm. However, there are still some disadvantages in the FOA, such as low convergence precision, easily trapped in a local optimum value at the later evolution stage. This paper presents an improved FOA based on the cell communication mechanism (CFOA), by considering the information of the global worst, mean, and best solutions into the search strategy to improve the exploitation. The results from a set of numerical benchmark functions show that the CFOA outperforms the FOA and the PSO in most of the experiments. Further, the CFOA is applied to optimize the controller for preoxidation furnaces in carbon fibers production. Simulation results demonstrate the effectiveness of the CFOA.

\section{Introduction}

As we all know, there are a lot of bioinspired optimization algorithms that are applied in practical engineering successfully, such as genetic algorithm (GA) inspired by the genetic science and natural selection $[1,2]$, particle swarm optimization (PSO) algorithm inspired by the simulation of the behavior of birds in nature [3-5], artificial bee colony (ABC) algorithm inspired by the intelligent behavior of honeybee swarm [6], artificial immune algorithm (AIA) inspired by the biological immune system [7-10], and ant colony optimization (ACO) algorithm inspired by the foraging behavior of the real ants [11].

By simulating the foraging behavior of fruit fly swarm, Pan [12] recently proposed a new kind of optimization algorithm called fruit fly optimization algorithm (FOA) for financial distress model. The FOA has some advantages, such as a simple structure to be realized with computer and ease of understanding. Since its invention in 2011, the FOA has been applied in many kinds of practical problems. Li et al. [13] applied the FOA to the forecasting problem of power load in electric power industry. Lin [14] used the FOA to optimize artificial neural network for analysis of service satisfaction in Web auction logistics service. Sheng and Bao [15] applied the FOA to search the optimal parameters values of the fractional order fuzzy-PID controller. Tu et al. [16] used the FOA to optimize generalized regression neural network for studying on business performance. $\mathrm{Li}$ et al. [17] used the FOA to optimize the two parameters for the least squares support vector machine to forecast the annual electricity consumption in China. Chen et al. [18] used the FOA to optimize the grey neural network model to perform satisfaction analysis for e-business service. According to all kinds of applications mentioned above, the FOA seems to be an excellent optimization algorithm. However, there is still an insufficiency in the FOA regarding the search strategy, which is used to produce new candidate solutions of the FOA based on the random information of foregoing solutions.

In order to overcome the lack of search strategy control mechanism in the basic FOA leading to poor quality of solution, in this paper, inspired by the cell communication mechanism, we propose an improved FOA based on the cell communication mechanism (CFOA) by incorporating the information of the global worst, mean, and best solutions 
into the search strategy to improve the exploitation. A set of numerical experiment results on function optimization [1922] show that the CFOA has excellent global optimization capability and the ability to obtain accurate solution. And its convergence speed is faster than that of the PSO and the FOA. Further, we apply the CFOA to optimize the controller for preoxidation furnaces in carbon fibers production. Simulation results demonstrate the effectiveness of the CFOA.

Carbon fibers are produced mainly from polyacrylonitrile (PAN), pitch, and rayon. Attributing to intrinsic composites, the PAN-based carbon fibers have maintained their dominant position in the market of engineering materials. It has been documented that more than $90 \%$ of world's total carbon fibers produced today are made from the PAN precursor [23]. Their high specific modulus and outstanding fatigue characteristics, combined with their lower weight and stiffness, make these fibers attractive for wide applications ranging from sporting goods to engineering components [24]. It is well known that the preoxidation process is one of the most basic and necessary stages in the conversion process from the PAN fibers to high specific strength carbon fibers. For example, Young's modulus of carbon fibers can be increased by high temperature treatment [25]. Although the preoxidation has been widely used in the production line of carbon fibers, it has not been given too much attention and few detailed studies of temperature control are presently available. Wangxi et al. [26] referred to the evolution of structure and properties of the PAN precursors in the process of preoxidation. Yu et al. [27] monitored the processing of preoxidation through their experimental results which indicated that the percent of $\mathrm{O}$ increases remarkably along with the gradual decrease of $\mathrm{C}$, $\mathrm{H}$, and $\mathrm{N}$. Hou et al. [28] investigated the influence of ozone on chemical reactions during the preoxidation process of the PAN as a carbon fiber precursor. Xue et al. [29] investigated the oxygen-induced modification of the PAN-based carbon fibers during the final stage of thermal-oxidative stabilization which is used to control the degree of chemical reactions and the radial structural homogeneity of fibers. However, most of the previous work was focused on analyzing the properties of carbon fibers by means of physical or chemical instruments, and little was concerning the control effect of the temperature on preoxidation reactions. Therefore, further studies are very essential from the point of view for improving the properties of carbon fibers in actual product, decreasing the cost wasting in practical production, and increasing the yield of carbon fibers.

The main contributions of this paper include the following aspects: (1) We propose the CFOA, which pushes forward the development of intelligent computing; (2) The CFOA is used to optimize the controller for preoxidation furnaces in carbon fibers production. With the proposed approach, we can control the temperature of preoxidation reactions, reducing not only wasted time but also energy consumption.

The main structure of this paper is organized as follows. Section 2 proposes the improved fruit fly optimization algorithm with cell communication mechanism. Section 3 provides the test of applying the proposed algorithm in finding minimal values of numerical benchmark functions. Section 4 applied the CFOA to the optimal control model of

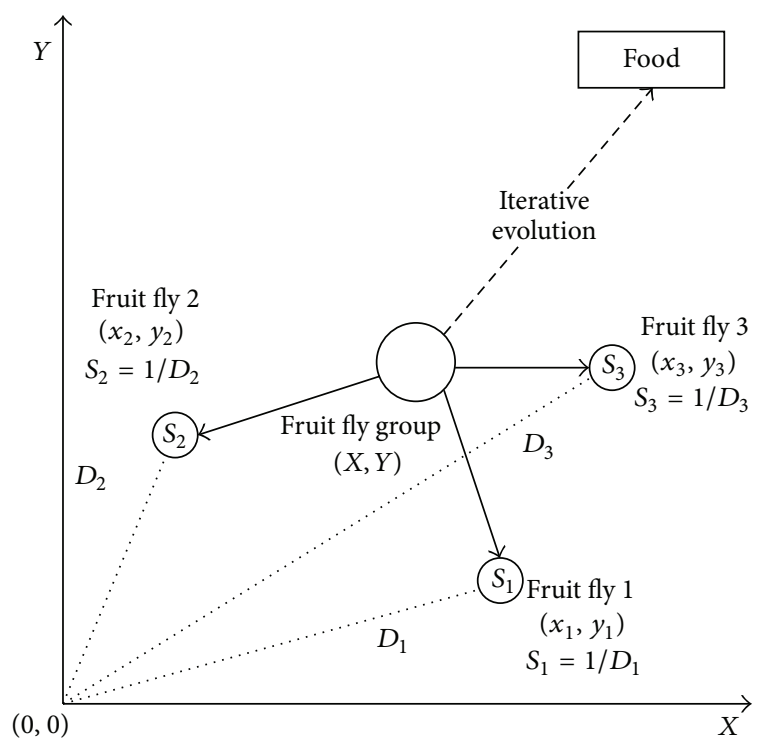

FIGURE 1: Food searching iterative process of fruit flies.

preoxidation furnace for producing the PAN-based carbon fibers and compares the results with the former methods. Section 5 concludes the paper.

\section{An Improved Fruit Fly Optimization Algorithm with Cell Communication}

2.1. The Fruit Fly Optimization Algorithm. The FOA is a new swarm intelligent method based on fruit fly's foraging behaviors, and it belongs to a kind of interactive evolutionary computation. Fruit flies are very small ones to eat fruit and rotting plants, which widely exist in temperate and tropical climate zones around the world. Fruit flies have visual and olfactory senses better than other species. They can easily make good search of various odors floating in the air with their olfactory organ or even smell the food sources $40 \mathrm{~km}$ away from them. Then, they would fly to the food by their sensitive vision. The food finding process made by the fruit fly can be summarized into the following steps: (1) firstly, smelling the food source by olfactory organ and flying towards that location; (2) secondly, getting close to the food location by their sensitive visions; (3) at last, other fruit flies' flocking location and flying towards that direction. Figure 1 [13] shows the food searching iterative process of fruit fly.

According to the food finding characteristics of fruit fly swarm, the FOA can be divided into seven steps as follows.

Step 1. Parameters initialization: the main parameters of the FOA are the total evolution number, the population size pop, and the initial fruit fly swarm location $\left(X_{0}, Y_{0}\right)$.

Step 2. Population initialization:

$$
\begin{aligned}
& X_{i}=X_{0}+\text { rand } \\
& Y_{i}=Y_{0}+\text { rand }
\end{aligned}
$$


Step 3. Computation of distance $\left(D_{i}\right)$ and smell $\left(S_{i}\right)$ :

$$
\begin{gathered}
D_{i}=\sqrt{X_{i}^{2}+Y_{i}^{2}}, \\
S_{i}=\frac{1}{D_{i}} .
\end{gathered}
$$

Step 4. Computation of the fitness function $\left(f_{i}\right)$ :

$$
f_{i}=f\left(S_{i}\right)
$$

Step 5. Find out the minimum individual fruit fly with the best fitness function $\left(f_{b}\right)$ among the fruit fly swarm:

$$
\text { [best } X \text { bestindex] }=\min \left(f\left(S_{i}\right)\right) \text {. }
$$

Step 6. Selection operation: keep the best fitness function value and coordinates $\left(X_{b}, Y_{b}\right)$. Then, the fruit fly swarm flies towards that location with the best fitness function value by using vision:

$$
\begin{gathered}
f_{b}=\text { best } X, \\
X_{b}=X(\text { bestindex }), \\
Y_{b}=Y \text { (bestindex). }
\end{gathered}
$$

Step 7. Judge if the stopping condition is satisfied. If not, go to Step 2; otherwise, stop the circulation.

\subsection{The Basic Characteristic of the Cell Communication. Cell} communication refers to a message through a medium to another cell and interacts with corresponding receptors of target cells, and after that a series of physiological changes taking place in the interior of cells. Indeed, cells can not survive in isolation and survive by receiving and processing information from the external environment. Cell to cell communication is essential for coordination of cellular events in multicellular systems [30]. Intercellular communication has three main ways: gap junction, cell recognition, and chemical communication.

Gap junction: narrow water-filled channels that connect the cytoplasm of adjacent epithelial cells, as well as of some other types of cells.

Cell recognition: mutual recognition among cells, usually with specific complementary interaction among their respective surface molecules or membrane glycoproteins.

Chemical communication: cells secrete some chemicals (such as hormone) to the external cells, as a signal molecule in target cells, adjust their function.

Based on the three main ways of cell communication, three evolutionary strategies are established. In particular, the gap junction, the cell recognition, and the chemical communication in the mode of cell communication can be used in the iterative and evolutionary process, respectively.

\subsection{The CFOA Based on the Cell Communication Mechanism.} Although the FOA has been applied in several fields, it still suffers with some degree of premature convergence and poor quality of solution, especially in solving higher

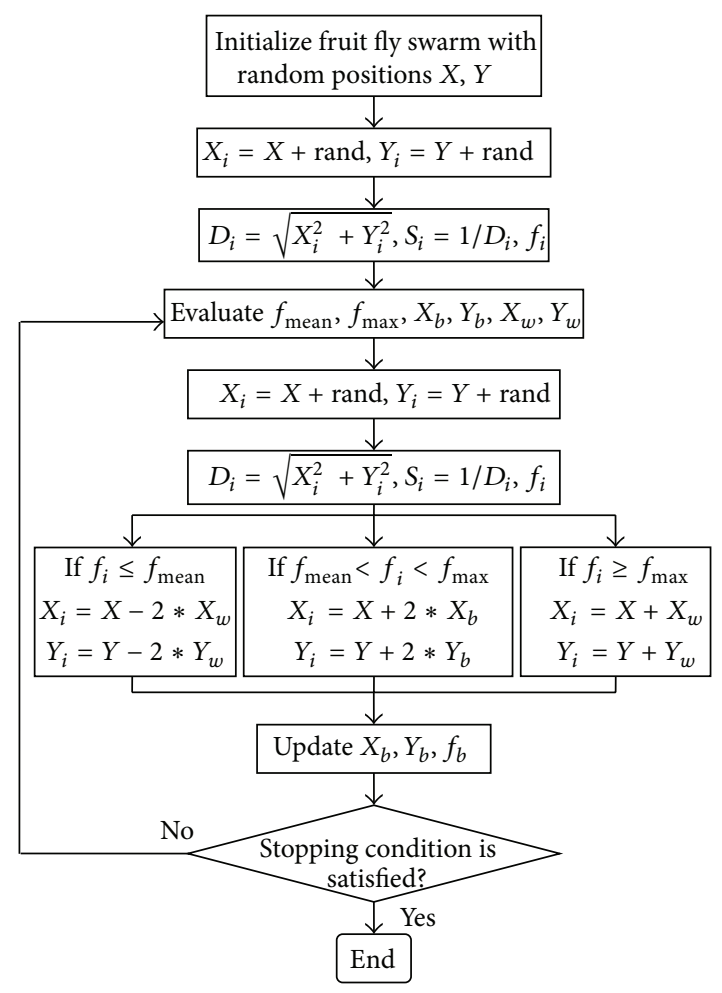

FIgURE 2: The implement procedure of the CFOA.

dimension multimodal objective functions. To overcome the shortcomings, we present the CFOA by combining the cell communication mechanisms. The CFOA applies the modified update formula to maintain the population diversity and enhances the convergence velocity and precision by incorporating the information of the global worst, mean, and best solutions into the search strategy to improve the exploitation. The CFOA has three major steps: (1) randomly generate a fruit fly swarm's initial position; (2) get the smell concentrations at positions of each and every fruit fly; and (3) assign each fruit fly a direction and distance for its movement to look for food with the modified update formula. The main steps are described as follows and their implementation procedure is illustrated in Figure 2.

According to the food searching characteristics of fruit flies, the CFOA can be divided into eleven steps as follows.

Step 1. Parameters initialization: the main parameters of the CFOA are the total evolution number, the population size pop, and the initial fruit fly swarm location.

Step 2. Population initialization: give the random flight direction and the distance for food searching of a fruit fly by using olfactory model (1).

Step 3. Compute the $D_{i}$ and the $S_{i}$ from formulas (2).

Step 4. Compute the $f_{i}$ by formula (3). 
TABLE 1: Benchmark functions definition [19-22].

\begin{tabular}{ll}
\hline Name & Definition \\
\hline Schaffer & $f_{1}(x)=0.5+\frac{\left(\sin \sqrt{\sum_{i=1}^{n} x_{i}^{2}}\right)^{2}-0.5}{\left(1+0.001\left(\sum_{i=1}^{n} x_{i}^{2}\right)\right)^{2}}$ \\
\hline Rosenbrock & $f_{2}(x)=\sum_{i=1}^{n}\left(100\left(x_{i}^{2}-x_{i+1}\right)^{2}+\left(x_{i}-1\right)^{2}\right)$ \\
\hline Sphere & $f_{3}(x)=\sum_{i=1}^{n} x_{i}^{2}$ \\
\hline Griewank & $f_{4}(x)=\frac{1}{4000} \sum_{i=1}^{n} x_{i}^{2}-\prod_{i=1}^{n} \cos \left(\frac{x_{i}}{\sqrt{i}}\right)+1$ \\
\hline Rastrigin & $f_{5}(x)=\sum_{i=1}^{n}\left[x_{i}^{2}-10 \cos \left(2 \pi x_{i}\right)+10\right]$ \\
\hline Ackley & $f_{6}(x)=20+e-20 \exp \left(-0.2 \sqrt{\frac{1}{n} \sum_{i=1}^{n} x_{i}^{2}}\right)-\exp \left(\frac{1}{n} \sum_{i=1}^{n} \cos 2 \pi x_{i}\right)$ \\
\hline
\end{tabular}

TABLE 2: Results for 5D functions.

\begin{tabular}{|c|c|c|c|c|c|c|}
\hline Function & $\mathrm{C}$ & Range & Comparison & FOA & CFOA & PSO \\
\hline \multirow{4}{*}{$f_{1}$} & \multirow{4}{*}{$\mathrm{MN}$} & \multirow{4}{*}[-600,600]{} & Best & $4.35 e-004$ & $\mathbf{0}$ & 0.0049 \\
\hline & & & Worst & $5.83 e-004$ & $\mathbf{0}$ & 0.0190 \\
\hline & & & Average & $4.99 e-004$ & $\mathbf{0}$ & 0.0119 \\
\hline & & & Std.Dev & $5.07 e-005$ & $\mathbf{0}$ & 0.0074 \\
\hline \multirow{4}{*}{$f_{2}$} & \multirow{4}{*}{$\mathrm{UN}$} & \multirow{4}{*}[-600,600]{} & Best & 3.9574 & $4.35 e-005$ & 0.4423 \\
\hline & & & Worst & 5.3111 & 0.5691 & 4.6508 \\
\hline & & & Average & 4.3386 & 0.1271 & 1.9483 \\
\hline & & & Std.Dev & 0.5844 & 0.1972 & 1.5192 \\
\hline \multirow{4}{*}{$f_{3}$} & \multirow{4}{*}{ US } & \multirow{4}{*}[-600,600]{} & Best & $4.24 e-004$ & $\mathbf{0}$ & $6.49 e-007$ \\
\hline & & & Worst & $5.34 e-004$ & $2.57 e-142$ & $1.76 e-004$ \\
\hline & & & Average & $4.71 e-004$ & $2.57 e-143$ & $7.41 e-005$ \\
\hline & & & Std.Dev & $3.15 e-005$ & $8.12 e-143$ & $5.93 e-005$ \\
\hline \multirow{4}{*}{$f_{4}$} & \multirow{4}{*}{$\mathrm{MN}$} & \multirow{4}{*}[-600,600]{} & Best & $9.61 e-005$ & $\mathbf{0}$ & $5.12 e-007$ \\
\hline & & & Worst & 0.0141 & $2.6024 \mathrm{e}-013$ & $2.61 e-004$ \\
\hline & & & Average & 0.0015 & $2.6024 \mathrm{e}-014$ & $3.98 e-005$ \\
\hline & & & Std.Dev & 0.0044 & $8.2294 \mathrm{e}-014$ & $7.93 e-005$ \\
\hline \multirow{4}{*}{$f_{5}$} & \multirow{4}{*}{ MS } & \multirow{4}{*}[-600,600]{} & Best & 0.0873 & $\mathbf{0}$ & 1.0681 \\
\hline & & & Worst & 19.748 & $\mathbf{0}$ & 3.9807 \\
\hline & & & Average & 4.5809 & $\mathbf{0}$ & 2.7500 \\
\hline & & & Std.Dev & 7.4937 & $\mathbf{0}$ & 0.8968 \\
\hline \multirow{4}{*}{$f_{6}$} & \multirow{4}{*}{$\mathrm{MN}$} & \multirow{4}{*}[-600,600]{} & Best & 0.0413 & $1.09 e-010$ & 0.0071 \\
\hline & & & Worst & 1.2502 & 0.0047 & 0.1863 \\
\hline & & & Average & 0.1642 & $5.28 \mathrm{e}-004$ & 0.0342 \\
\hline & & & Std.Dev & 0.3816 & 0.0015 & 0.0539 \\
\hline
\end{tabular}

Step 5. Compute the mean fitness function

$$
f_{\text {mean }}=\frac{\sum_{i=1}^{n} f\left(S_{i}\right)}{n} .
$$

Step 6. Find out the minimum individual fruit fly with the $f_{b}$ among the fruit fly swarm using formulas (4)-(5).
Step 7. Find out the maximal individual fruit fly with the worst fitness function $\left(f_{\max }\right)$ among the fruit fly swarm:

$$
\text { [worst } X \text { worstindex] }=\max \left(f\left(S_{i}\right)\right) \text {, }
$$

$$
f_{\max }=\text { worst } X \text {, }
$$$$
X_{w}=X \text { (worstindex), }
$$$$
Y_{w}=Y \text { (worstindex) . }
$$ 
TABLE 3: Results for 30D functions.

\begin{tabular}{|c|c|c|c|c|c|c|}
\hline Function & $\mathrm{C}$ & Range & Comparison & FOA & CFOA & PSO \\
\hline \multirow{4}{*}{$f_{1}$} & \multirow{4}{*}{$\mathrm{MN}$} & \multirow{4}{*}[-600,600]{} & Best & 0.0031 & 0 & 0.0049 \\
\hline & & & Worst & 0.6099 & $\mathbf{0}$ & 0.0190 \\
\hline & & & Average & 0.1602 & $\mathbf{0}$ & 0.0176 \\
\hline & & & Std.Dev & 0.2539 & $\mathbf{0}$ & 0.0045 \\
\hline \multirow{4}{*}{$f_{2}$} & \multirow{4}{*}{$\mathrm{UN}$} & \multirow{4}{*}[-600,600]{} & Best & 28.707 & $7.90 e-05$ & 88.072 \\
\hline & & & Worst & 108.70 & 0.4244 & 166.19 \\
\hline & & & Average & 72.133 & 0.0811 & 136.16 \\
\hline & & & Std.Dev & 26.257 & 0.1359 & 26.393 \\
\hline \multirow{4}{*}{$f_{3}$} & \multirow{4}{*}{ US } & \multirow{4}{*}[-600,600]{} & Best & 0.0029 & $\mathbf{0}$ & 0.4305 \\
\hline & & & Worst & 1.5799 & $1.7617 e-141$ & 1.7187 \\
\hline & & & Average & $5.13 e-001$ & $1.7617 \mathrm{e}-142$ & 1.1396 \\
\hline & & & Std.Dev & 0.5270 & $5.5710 \mathrm{e}-142$ & 0.4359 \\
\hline \multirow{4}{*}{$f_{4}$} & \multirow{4}{*}{$\mathrm{MN}$} & \multirow{4}{*}[-600,600]{} & Best & $1.92 e-004$ & $\mathbf{0}$ & 0.0444 \\
\hline & & & Worst & 0.0588 & $7.40 e-003$ & 0.1181 \\
\hline & & & Average & 0.0210 & $7.44 e-004$ & 0.0703 \\
\hline & & & Std.Dev & 0.0236 & 0.0024 & 0.0212 \\
\hline \multirow{4}{*}{$f_{5}$} & \multirow{4}{*}{ MS } & \multirow{4}{*}[-600,600]{} & Best & 0.6323 & $\mathbf{0}$ & 67.382 \\
\hline & & & Worst & 128.24 & $\mathbf{0}$ & 140.63 \\
\hline & & & Average & 91.073 & $\mathbf{0}$ & 99.362 \\
\hline & & & Std.Dev & 49.057 & $\mathbf{0}$ & 27.050 \\
\hline \multirow{4}{*}{$f_{6}$} & \multirow{4}{*}{$\mathrm{MN}$} & \multirow{4}{*}[-600,600]{} & Best & 0.0446 & $-8.8818 e-016$ & 1.6693 \\
\hline & & & Worst & 1.8229 & 0.5775 & 2.3261 \\
\hline & & & Average & 0.9374 & 0.1225 & 1.9970 \\
\hline & & & Std.Dev & 0.7885 & 0.2328 & 0.3511 \\
\hline
\end{tabular}

Step 8. Update strategy: check each fruit fly's position using the following formulas:

$$
\text { If }\left(f_{i} \leq f_{\text {mean }}\right)
$$

Then

$$
\begin{aligned}
& X_{i}=X-2 * X_{w} \\
& Y_{i}=Y-2 * Y_{w}, \\
& \text { If }\left(f_{\text {mean }}<f_{i}<f_{\text {max }}\right)
\end{aligned}
$$

Then

$$
\begin{aligned}
& X_{i}=X+2 * X_{b} \\
& Y_{i}=Y+2 * Y_{b}, \\
& \text { If }\left(f_{i} \geq f_{\max }\right)
\end{aligned}
$$

Then

$$
\begin{aligned}
& X_{i}=X+X_{w} \\
& Y_{i}=Y+Y_{w} .
\end{aligned}
$$

Step 9. Find out the fruit fly with best fitness function among the fruit fly swarm:

$$
f_{b}=\min \left(f_{i}\right) \text {. }
$$

Step 10. Selection operation: keep $X_{b}, Y_{b}$, and $f_{b}$; then the fruit fly swarm flies towards the location with the best fitness function value by using vision.

Step 11. Judge if the stopping condition is satisfied. If not, go to enter the circulation; otherwise, get the output.

\section{Experimental Results with Benchmark Functions}

Our experiments are completed on an Intel Pentium Dual, CPU 2.4 GHZ, personal computer (PC) with $3 \mathrm{~GB}$ RAM under Windows XP. All simulations are implemented by using MATLAB_7.9 program.

3.1. Parameter Settings. In all the experiments, the values of the common parameters are chosen to be the same for all algorithms. The total evolution number is 100 , the initial range of $X$ is $[-600,600]$, and population size is 20 for all functions. The PSO algorithm to be compared is given below: social and cognitive components are both set to 2.0 [31]. Inertia weight, which influences the velocity of the particle in the next iteration, is set to be 0.6 [22]. Each of the experiments is repeated 10 times independently, and 
TABLE 4: Results for 50D functions.

\begin{tabular}{|c|c|c|c|c|c|c|}
\hline Function & $\mathrm{C}$ & Range & Comparison & FOA & CFOA & PSO \\
\hline \multirow{4}{*}{$f_{1}$} & \multirow{4}{*}{$\mathrm{MN}$} & \multirow{4}{*}[-600,600]{} & Best & 0.0049 & 0 & 0.2221 \\
\hline & & & Worst & 0.8832 & 0.6784 & 0.3296 \\
\hline & & & Average & 0.2576 & 0.0678 & 0.2755 \\
\hline & & & Std.Dev & 0.0387 & 0.2145 & 0.0037 \\
\hline \multirow{4}{*}{$f_{2}$} & \multirow{4}{*}{ UN } & \multirow{4}{*}[-600,600]{} & Best & 48.5100 & 48.6213 & 274.4630 \\
\hline & & & Worst & 178.0495 & 49.000 & 769.8354 \\
\hline & & & Average & 119.8091 & 48.9517 & 508.4547 \\
\hline & & & Std.Dev & 3.1920 & 0.1186 & 14.2781 \\
\hline \multirow{4}{*}{$f_{3}$} & \multirow{4}{*}{ US } & \multirow{4}{*}[-600,600]{} & Best & 0.8342 & $\mathbf{0}$ & 2.6038 \\
\hline & & & Worst & 1.9000 & 0.0123 & 6.1062 \\
\hline & & & Average & 1.3174 & 0.0012 & 3.5712 \\
\hline & & & Std.Dev & 0.0388 & 0.0039 & 0.0949 \\
\hline \multirow{4}{*}{$f_{4}$} & \multirow{4}{*}{$\mathrm{MN}$} & \multirow{4}{*}[-600,600]{} & Best & $2.2758 e-004$ & $\mathbf{0}$ & 0.0984 \\
\hline & & & Worst & 0.0738 & $\mathbf{0}$ & 0.1868 \\
\hline & & & Average & 0.0307 & $\mathbf{0}$ & 0.1401 \\
\hline & & & Std.Dev & 0.0028 & $\mathbf{0}$ & 0.0030 \\
\hline \multirow{4}{*}{$f_{5}$} & \multirow{4}{*}{ MS } & \multirow{4}{*}[-600,600]{} & Best & 58.7561 & $\mathbf{0}$ & 179.2948 \\
\hline & & & Worst & 248.6845 & 43.0351 & 264.6745 \\
\hline & & & Average & 172.1425 & 8.2006 & 225.2831 \\
\hline & & & Std.Dev & 6.3818 & 1.6426 & 2.6017 \\
\hline \multirow{4}{*}{$f_{6}$} & \multirow{4}{*}{$\mathrm{MN}$} & \multirow{4}{*}[-600,600]{} & Best & 0.0458 & $-8.8818 \mathrm{e}-016$ & 2.3402 \\
\hline & & & Worst & 1.5043 & 1.3538 & 2.9950 \\
\hline & & & Average & 0.8789 & 0.1354 & 2.5752 \\
\hline & & & Std.Dev & 0.0687 & 0.4281 & 0.0209 \\
\hline
\end{tabular}

the reported results are average, best, worst, and standard deviations of the statistical experimental data.

3.2. Experimental Results for Benchmark Functions. In the field of computational optimization, it is common to test different algorithms using plenty of test functions, especially when the test functions include various kinds of problems such as regular, irregular, separable, nonseparable unimodal, and multimodal problems. Multimodal functions which have more than one local optimal value are used to verify the ability of algorithms escaping from local minima. If an algorithm is poor that it can not be efficiently completed the search process during global searching, it gets stuck at the local optimal value. The tested benchmark functions are numbered as $f_{1}$ to $f_{6}$ and tabulated in Table 1 .

The experiments are tested on three groups of benchmark functions with dimension $(D)$ of 5, 30, and 50. The increment in the dimension of function increases the difficulty [22]. Hence, if an algorithm can find the global optimal values for many dimensions, it will be easily copied to the practical engineering problems. The performance of the CFOA is compared with that of the PSO and the FOA in terms of (1) the best result, (2) the worst result, (3) the average result, and (4) the standard deviation (Std. Dev) result. Initial range, formulation, dimensions, and the characteristics of these problems are listed in Tables $2-4$. In Tables $2-4, \mathrm{C}$ is characteristic; $\mathrm{U}$ is unimodal; $\mathrm{M}$ is multimodal; $\mathrm{S}$ is separable; and $\mathrm{N}$ is nonseparable.

3.2.1. Experiment 1. In Experiment 1, the performance of the CFOA has been compared to other optimization algorithms: the PSO and the FOA. Functions in the set are with low dimension. The worst, best, mean of best, and the standard deviations of the function values found after 10 runs are presented in Table 2. From the results in this table, it is clear that the CFOA is more precise on six functions. This is because the CFOA is a new strategy by incorporating the information of global best, worst, and mean solutions devised for optimal exploitation of local information. None of the three algorithms have found the optimal value on Rosenbrock and Ackley functions, but the result of the CFOA is better than the other two. On Schaffer, Griewank, and Rastrigin functions the CFOA have produced the optima. For space limitation, here we just present the convergence curves of the PSO, the FOA, and the CFOA to show the progresses of the mean of best function values presented in Figure 3. In order to make this clear, the interpretations of the convergence curves of the CFOA are described separately: Figure 3(b) is for Figure 3(a), Figure 3(e) is for Figure 3(d), Figure 3(g) is for Figure 3(f), and Figure 3(i) is for Figure 3(h), respectively.

3.2.2. Experiment 2. In Experiment 2, the performance of the CFOA has been compared with other optimization 


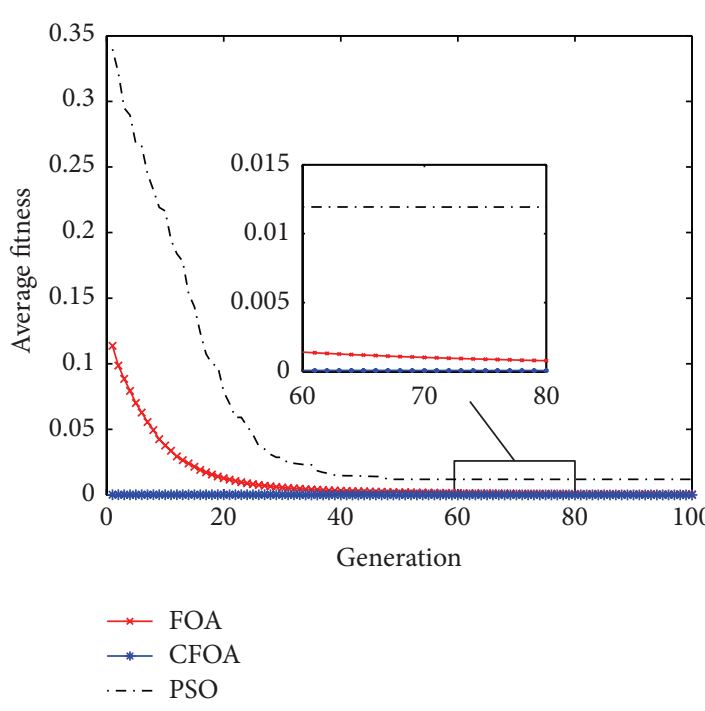

(a) Convergence curves for the Schaffer function

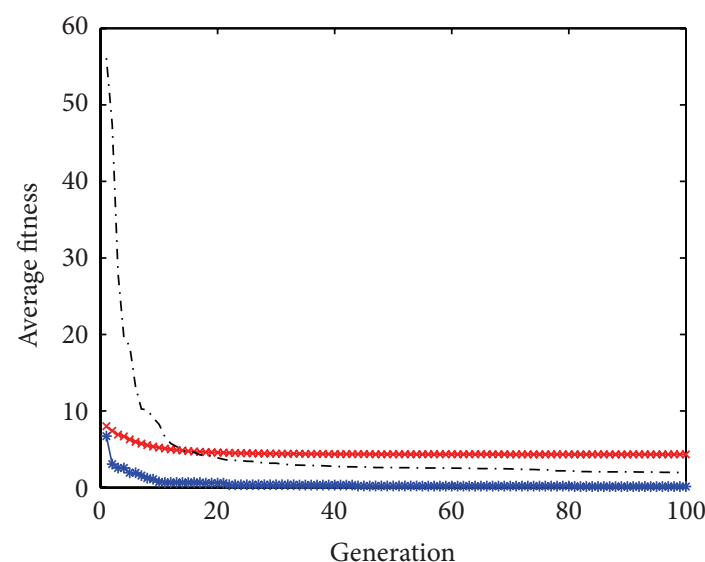

$\rightarrow$ FOA

$\rightarrow$ CFOA

... PSO

(c) Convergence curves for the Rosenbrock function

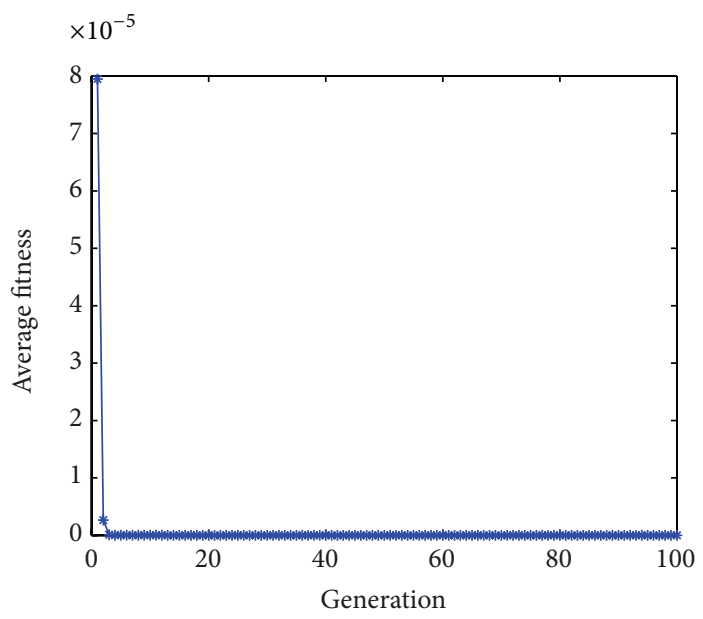

$\rightarrow$ CFOA

(e) Convergence curves of the CFOA for the Sphere function

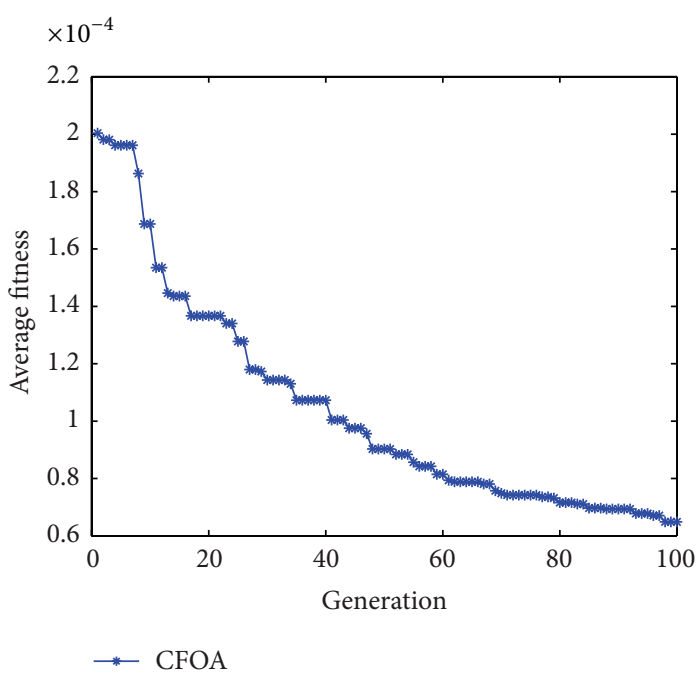

(b) Convergence curves of the CFOA for the Schaffer function

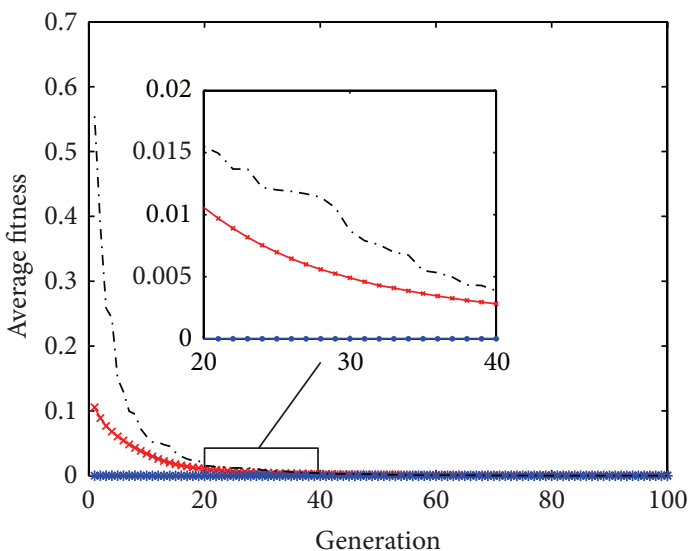

$\rightarrow$ FOA

$\rightarrow$ CFOA

-.. PSO

(d) Convergence curves for the Sphere function

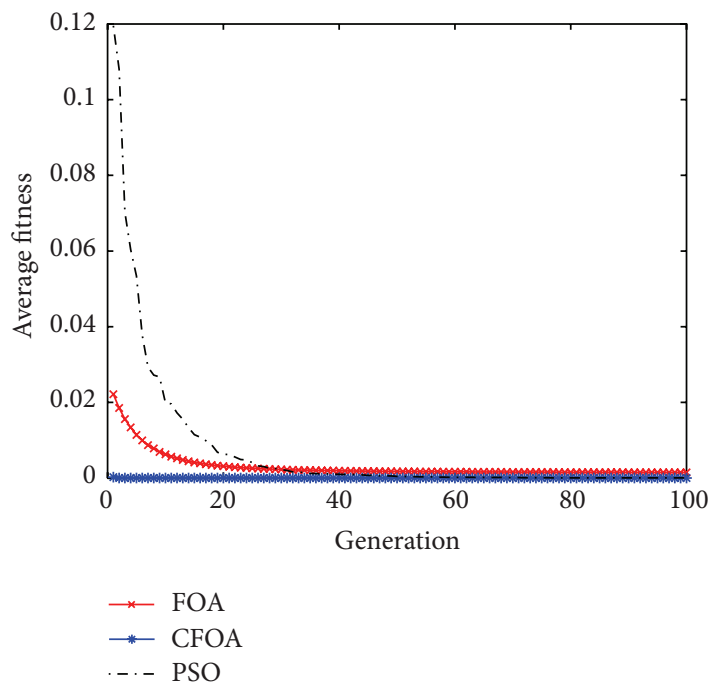

(f) Convergence curves for the Griewank function

Figure 3: Continued. 


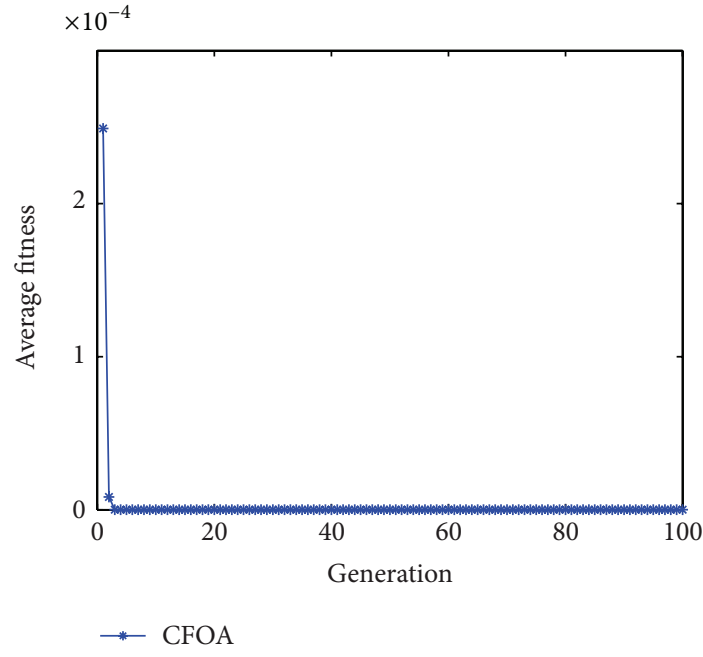

(g) Convergence curves of the CFOA for the Griewank function

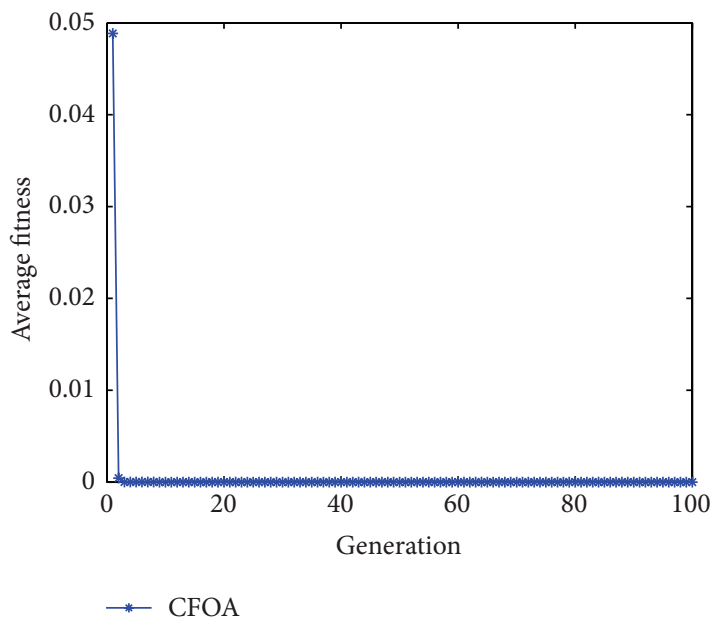

(i) Convergence curves of the CFOA for the Rastrigin function

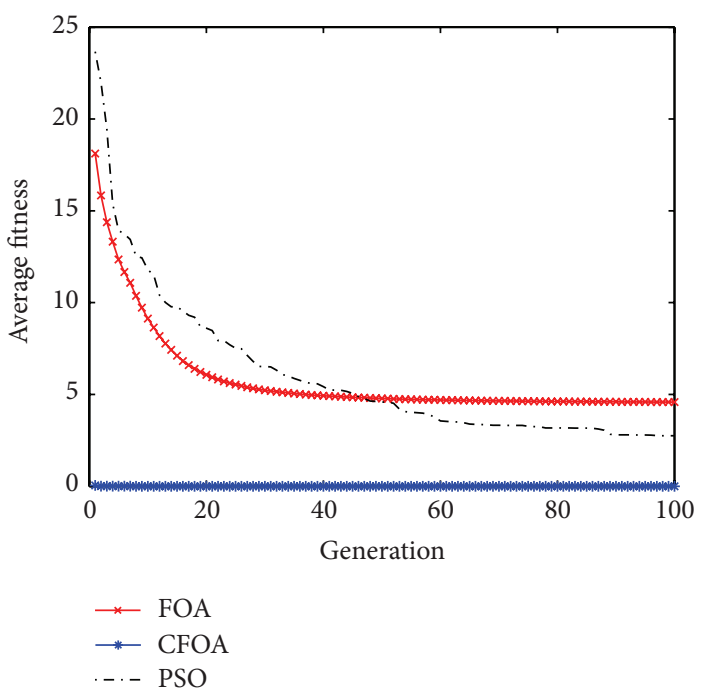

(h) Convergence curves for the Rastrigin function

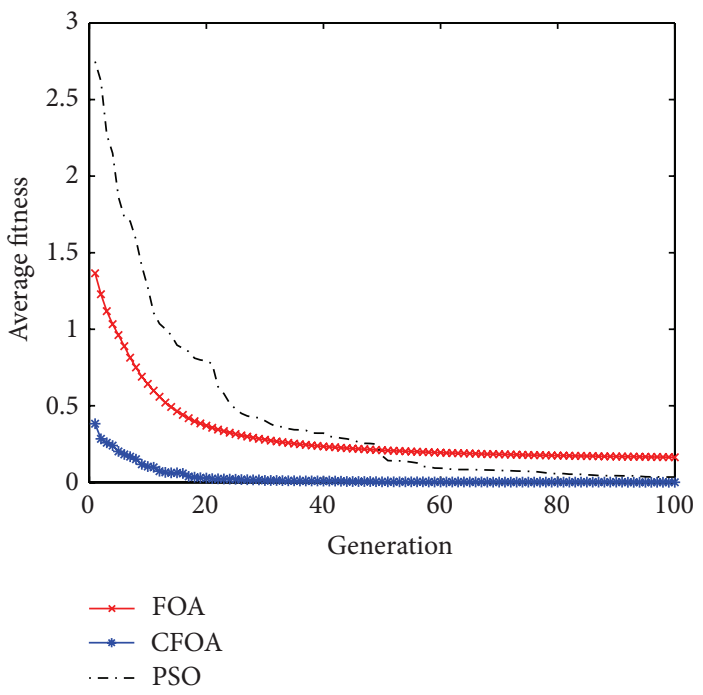

(j) Convergence curves for the Ackley function

FIgURE 3: Convergence graphs of the mean of best function values.

algorithms: the PSO and the FOA. From Table 3, for three algorithms, on Rosenbrock and Ackley functions none of the algorithms have found the optimal value, but the result of the CFOA is better than the other two. On Schaffer, Sphere, Griewank, and Rastrigin functions the CFOA have produced the optima. The CFOA shows better robustness on Schaffer and Rastrigin functions. For space limitation, here we just present the convergence curves of the PSO, the FOA, and the CFOA to show the progresses of the mean of best function values presented in Figure 4 . In order to make this clear, the interpretations of the convergence curves of the CFOA are described separately: Figure 4(b) is for Figure 4(a), Figure 4(d) is for Figure 4(c), Figure 4(f) is for Figure 4(e), and Figure $4(\mathrm{~h})$ is for Figure $4(\mathrm{~g})$, respectively.
3.2.3. Experiment 3. In Experiment 3, the performance of the CFOA has been compared with that of the PSO and the FOA. Functions in the set are not low dimensional; therefore, nonseparable functions are more difficult than the separable functions. The dimensionality of the search space is an important problem [32]. In some functions, the global minimum value is very small when compared to whole search space or is very close to the local ones (Schaffer). As for multimodal functions, if the algorithm cannot explore the search space effectively and cannot keep up the direction changes in the functions having narrow curving valley (Rosenbrock), it fails in these kinds of problems. From Table 4, for three algorithms, on Rosenbrock and Ackley functions none of the algorithms have produced the optimal value but the result of 


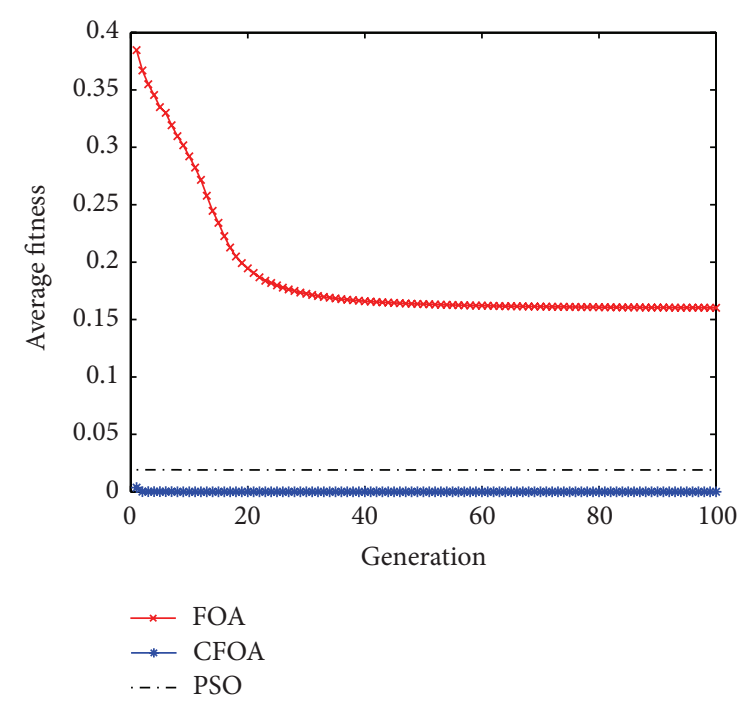

(a) Convergence curves for the Schaffer function

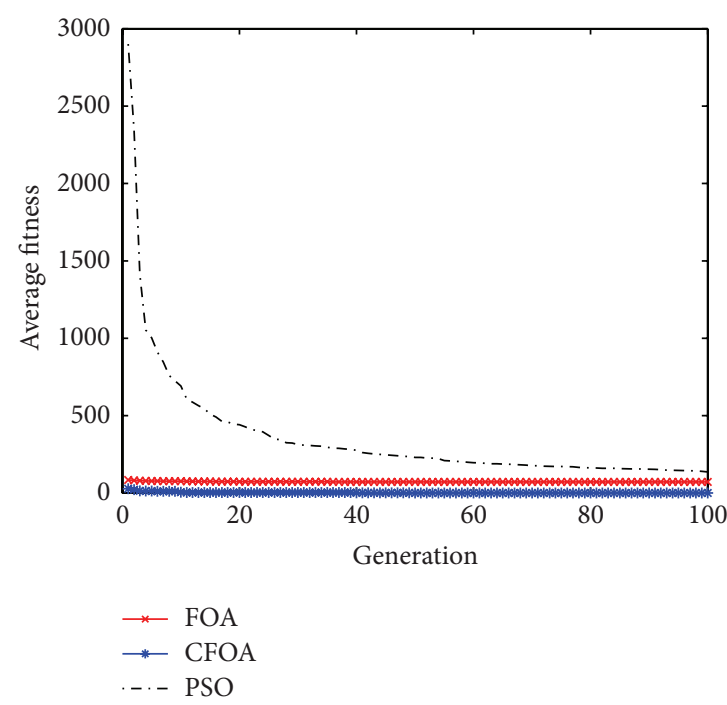

(c) Convergence curves for the Rosenbrock function

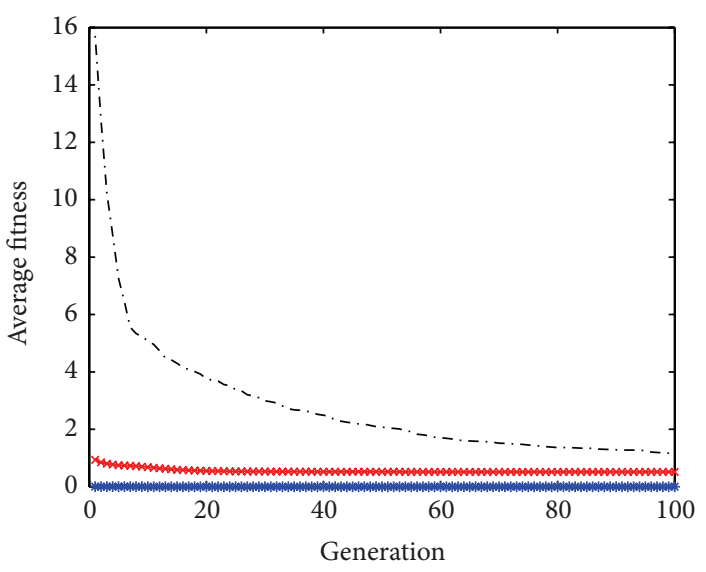

$\rightarrow$ FOA

$\rightarrow$ CFOA

... $\mathrm{PSO}$

(e) Convergence curves for the Sphere function

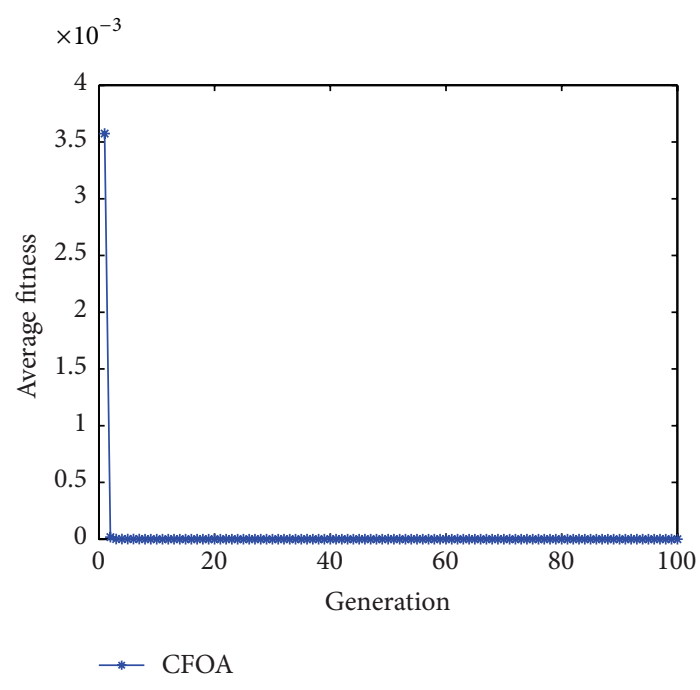

(b) Convergence curves of the CFOA for the Schaffer function

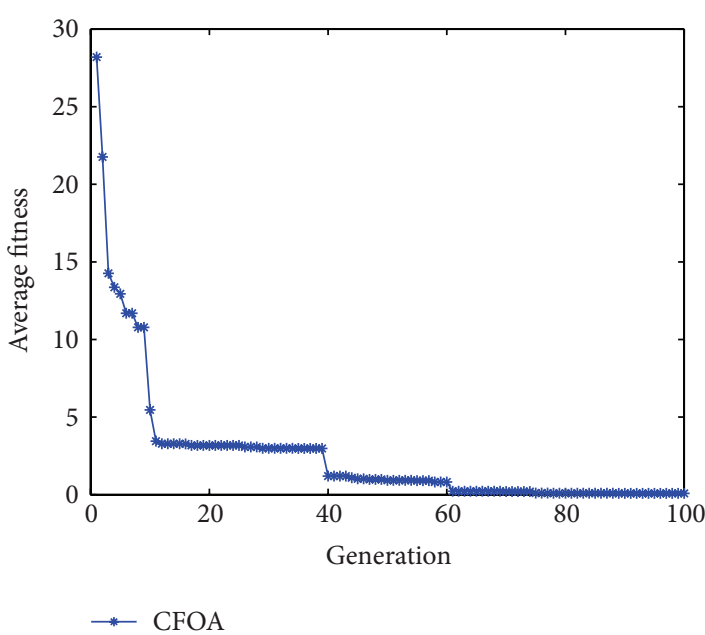

(d) Convergence curves of the CFOA for the Rosenbrock function

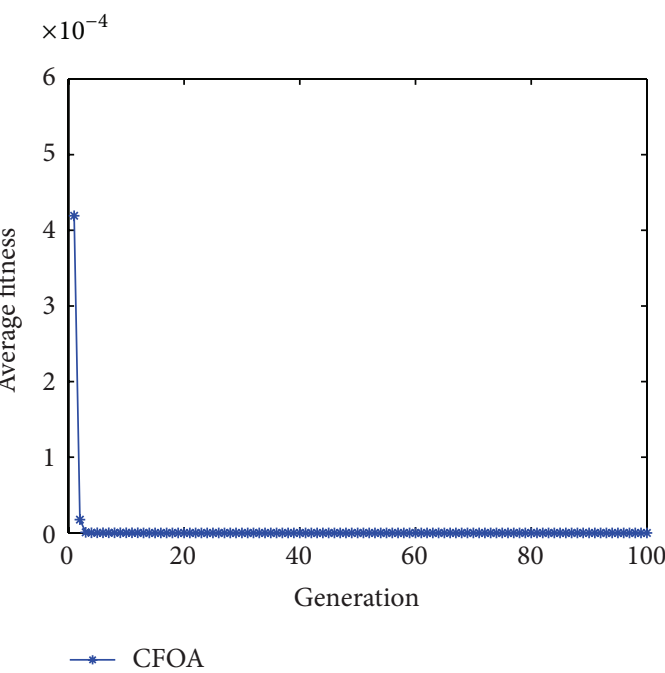

(f) Convergence curves of the CFOA for the Sphere function

Figure 4: Continued. 


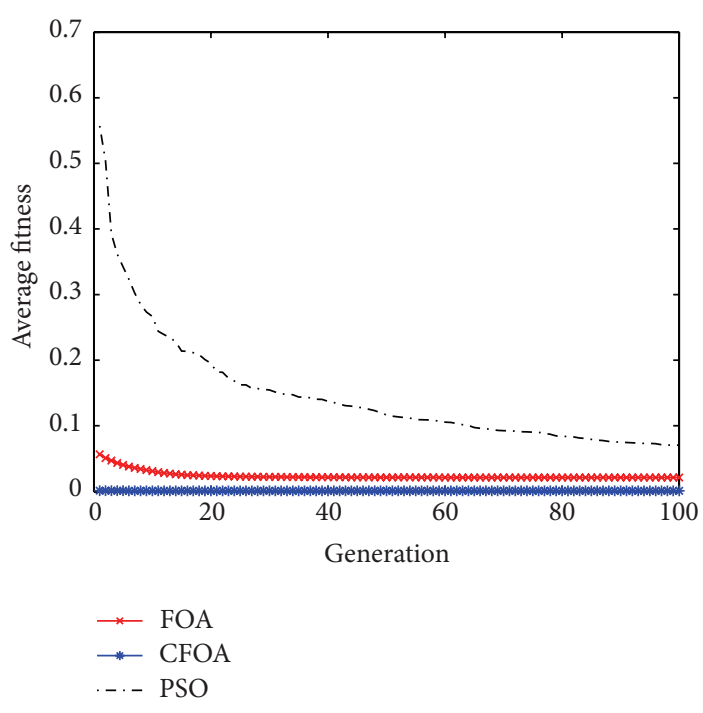

(g) Convergence curves for the Griewank function

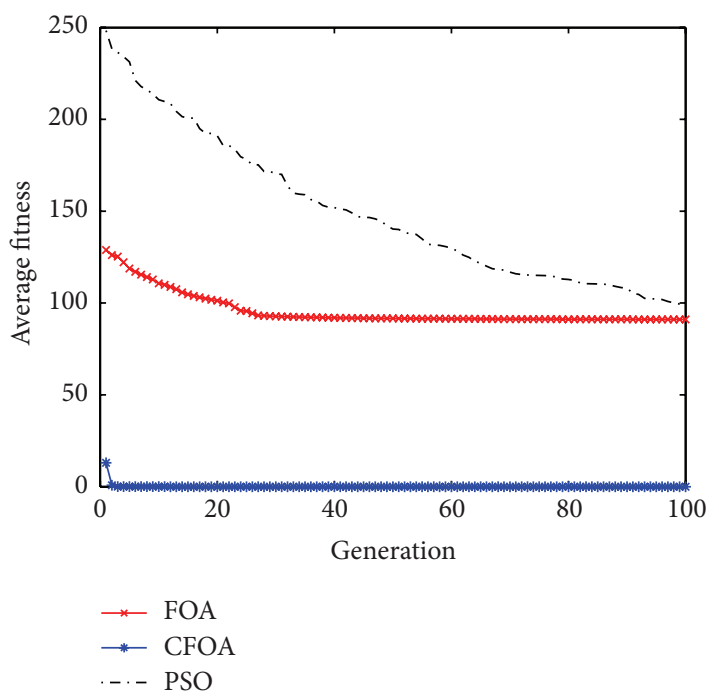

(i) Convergence curves for the Rastrigin function

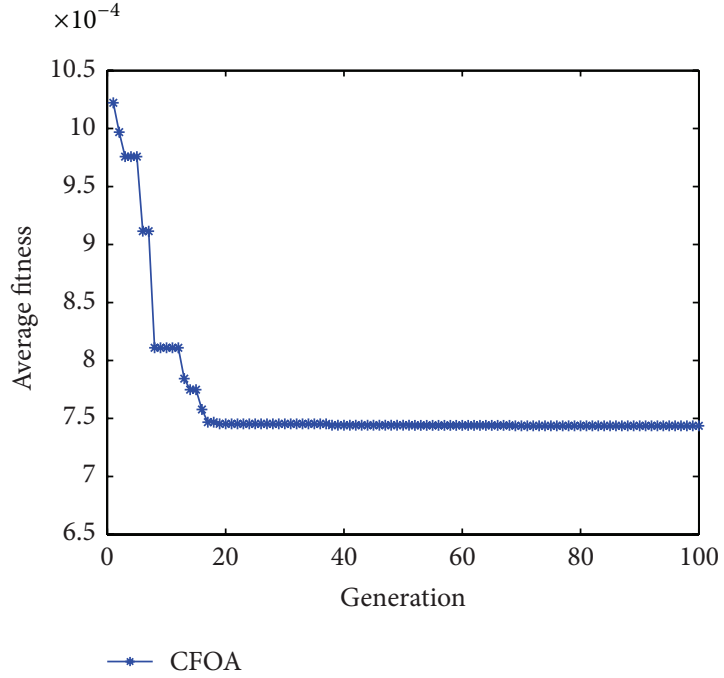

(h) Convergence curves of the CFOA for the Griewank function

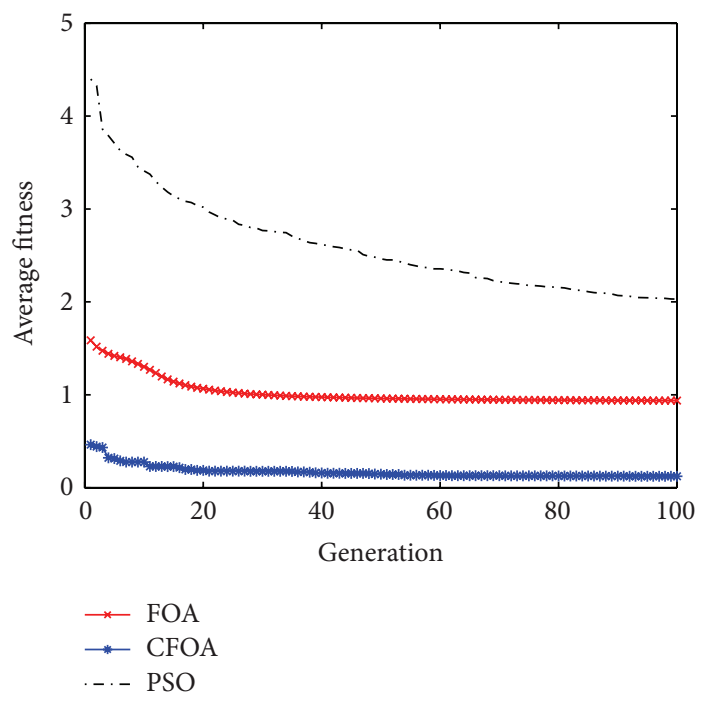

(j) Convergence curves for the Ackley function

FIGURE 4: Convergence graphs of the mean of the best function values.

the CFOA is better than the other two. On Schaffer, Sphere, Griewank, and Rastrigin functions the CFOA has produced the optima. In order to make this clear, the interpretations of the convergence curves of the CFOA are described separately: Figure 5(c) is for Figure 5(b) and Figure 5(e) is for Figure 5(d), respectively.

\section{The CFOA Applied to Optimize the Controller in Carbon Fibers Production}

4.1. Model of Preoxidation Furnace for Producing PAN-Based Carbon Fibers. Preoxidation is to pass the precursor tow through a furnace divided into several zones with increasing temperature gradient at $190-300^{\circ} \mathrm{C}$ in air [33], followed by a precarbonization and a carbonization [34]. A precarbonization treatment usually between 300 to $700^{\circ} \mathrm{C}$ is performed prior to carbonization. To avoid thermal shock of fibers, low temperature heat treatment is applied. Carbonization is carried out in an inert atmosphere at the highest temperature of $1400-1600^{\circ} \mathrm{C}$ and a total residence for a few minutes in oxygen-free atmosphere is applied, during which noncarbon elements are driven off and the high-strength inorganic carbonaceous fibrous materials are produced at last [35].

PAN precursor fibers are conducted continuously through preoxidation furnaces with 10 temperature zones in air at an initial feeding speed of $0.4 \mathrm{~m} / \mathrm{min}$, and then the preoxidized fibers are conducted through one low temperature carbonization furnace and one high temperature carbonization furnace. Through such a two-step process, carbon 


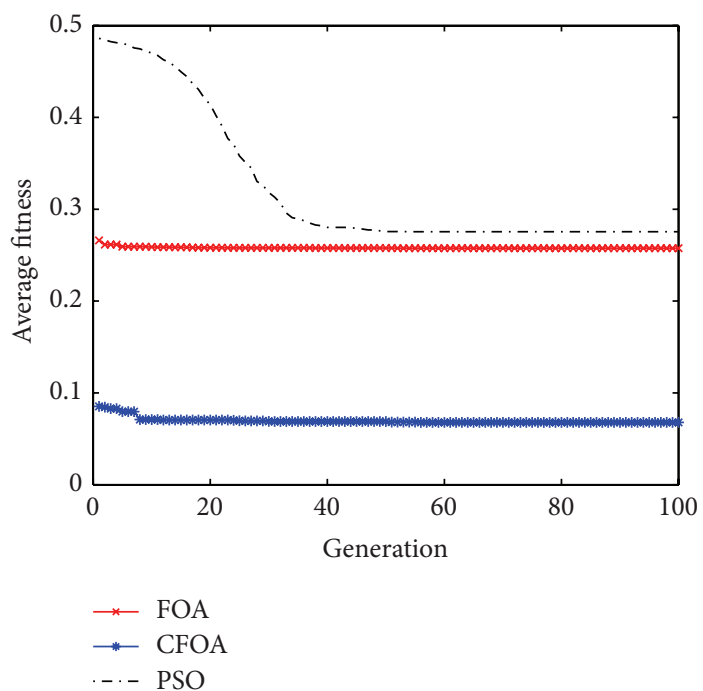

(a) Convergence curves for the Schaffer function

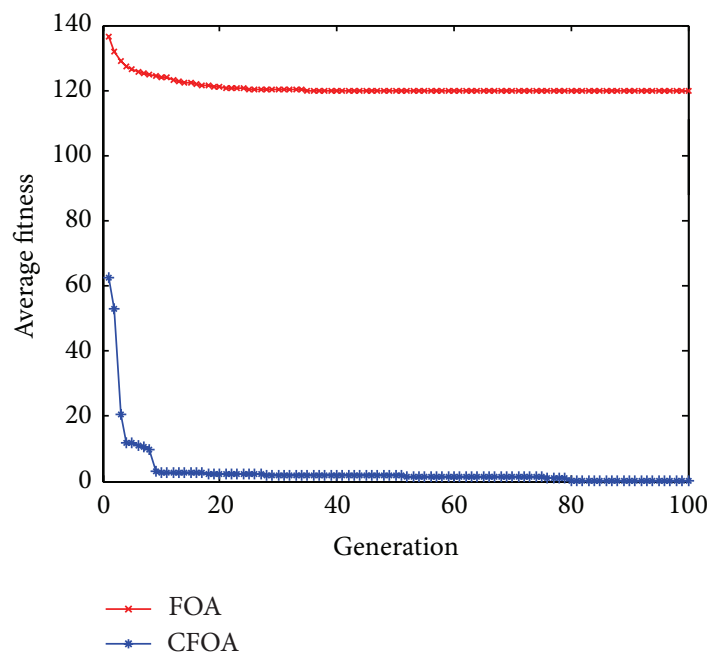

(c) Convergence curves of the CFOA for the Rosenbrock function

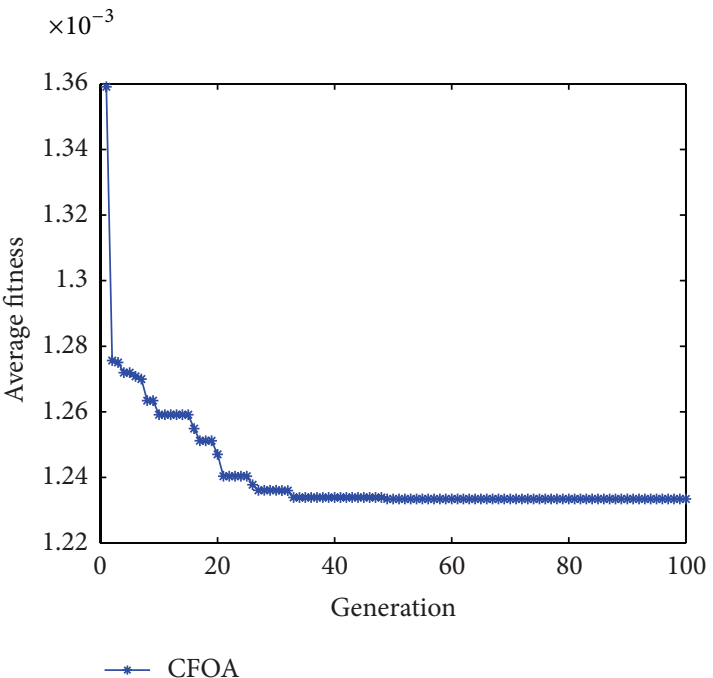

(e) Convergence curves of the CFOA for the Sphere function

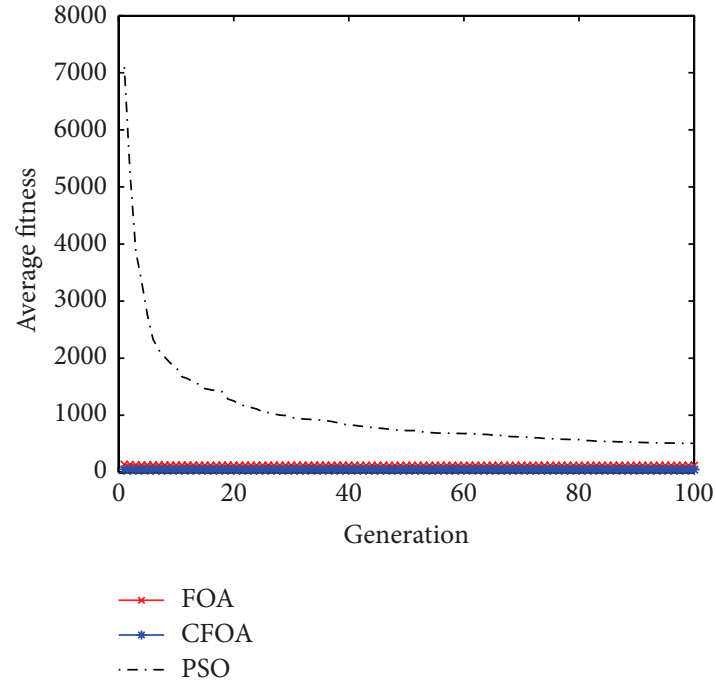

(b) Convergence curves for the Rosenbrock function

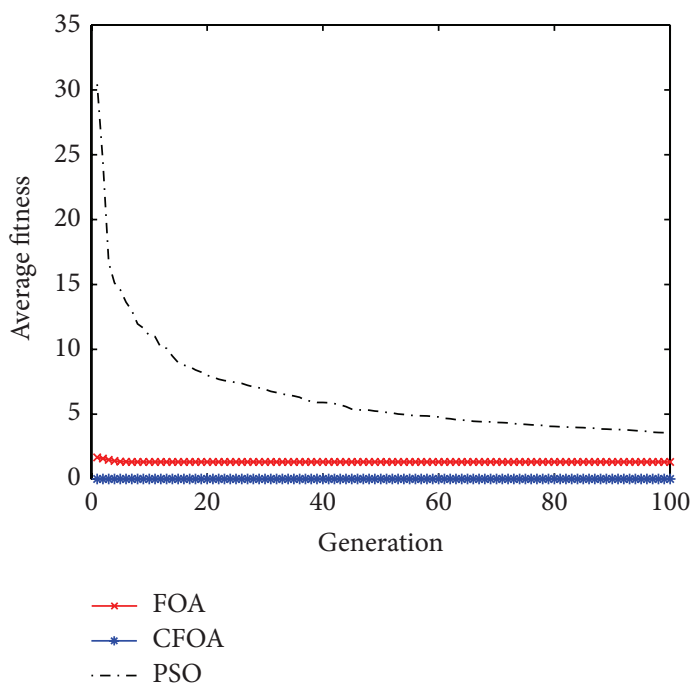

(d) Convergence curves for the Sphere function

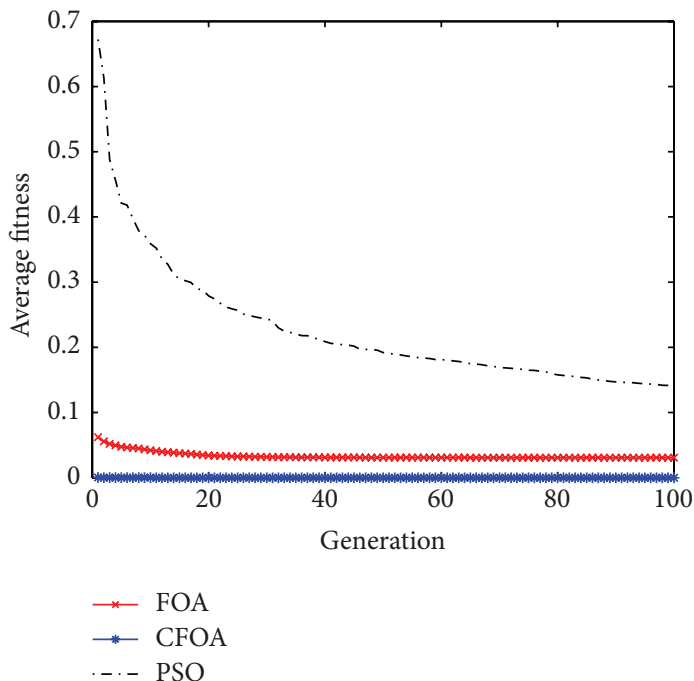

(f) Convergence curves for the Griewank function 


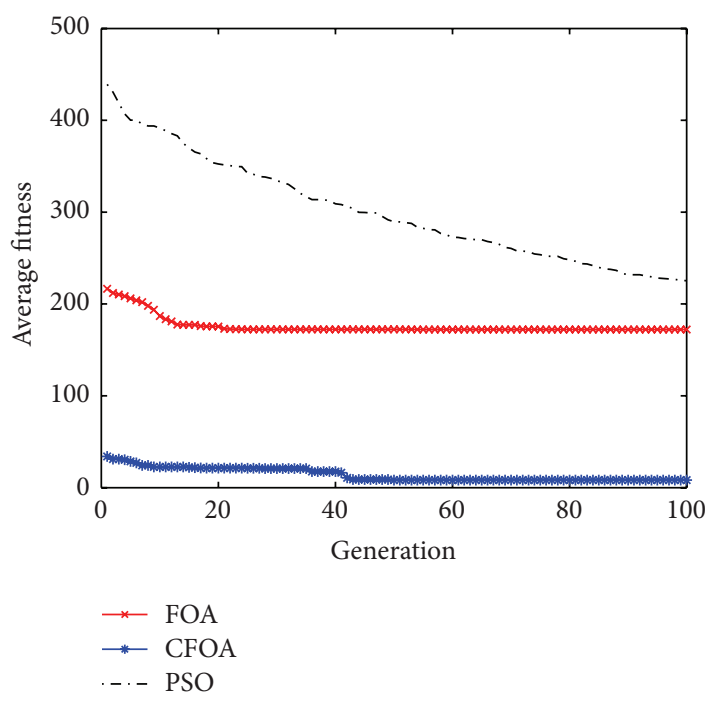

(g) Convergence curves for the Rastrigin function

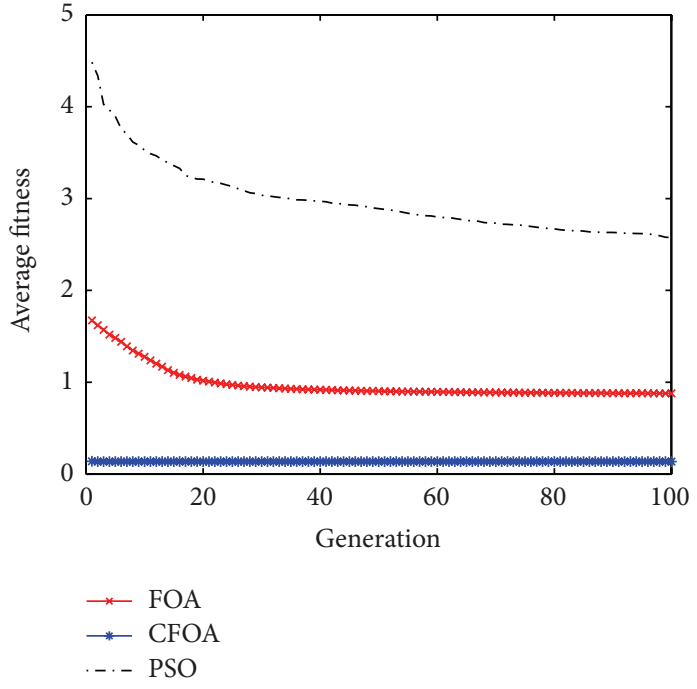

(h) Convergence curves for the Ackley function

FIGURE 5: Convergence graphs of the mean of best function values.

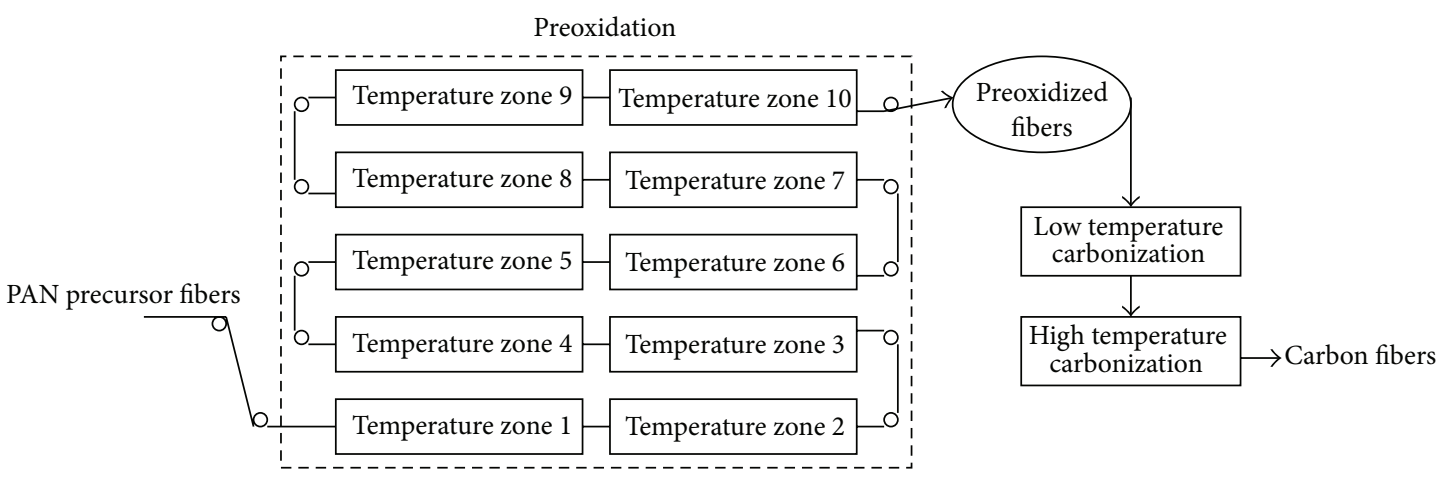

FIGURE 6: Schematic of continuous preoxidation and carbonization.

fibers can be obtained finally, and the detailed process is shown in Figure 6. The detailed temperatures of the 10 zones are programmed as 190-200-210-220-230-240-250-260-260$270^{\circ} \mathrm{C}$, as shown in Table 5 .

4.2. Optimal Control Model of Preoxidation Furnace. The diagram of the Smith-predictor control system by combining with the CFOA is shown in Figure 7, where $r$ is the desired input, $e$ is the system error between the desired output and the actual output, $u$ is the control force, and $y$ is the actual output. We wish to properly design a set of PI gains such that the system output response satisfies certain specifications. In the CFOA-based Smith-predictor control system, let $\Theta=$ $\left[\theta_{1}, \theta_{2}\right]=\left[K_{p}, K_{i}\right]$ be a parameter vector or a fruit fly.

The convergence of the CFOA toward the global optimal solution is guided by the objective function. Hence it should be properly defined before the CFOA is executed. The objective function is defined by the integral of the error (IE) as

$$
\mathrm{IE}=\int_{0}^{T_{i}} t(|r(t)-y(t)|) d t=\int_{0}^{T_{i}} t|e(t)| d t
$$

where $T_{i}$ is the time of integration. This function will be minimized by using the CFOA to obtain the optimal PI gains.

Preoxidization furnace is approximately a first-order system with time lag given as

$$
G(s)=\frac{K}{T s+1} e^{-\tau s},
$$

where $K$ is the process gain, $\tau$ is time delay, $T$ is time constant. The control model for preoxidization furnace with substituting the actual system parameters can be written as

$$
G(s)=\frac{50}{60 s+1} e^{-30 s} .
$$


(1) Begin

(2) Initialize fruit fly swarm with random position $X_{0}, Y_{0} \in[0,300]$

(3) Give the random direction and distance for search of food, set $G=0$ $X_{i}=X_{0}+$ rand, $\quad Y_{i}=Y_{0}+$ rand

(4) The smell concentration judgment value $\left(S_{i}\right)$ is the reciprocal of the distance of the food location to the origin $\left(D_{i}\right)$

$D_{i}=\sqrt{X_{i}^{2}+Y_{i}^{2}}, \quad S_{i}=1 / D_{i}, \quad S_{i}=\left[K_{p}, K_{i}\right]$

(5) Evaluate the corresponding objective function $I E_{i}$ of every fruit fly and record each fruit fly's best previous position $\left(X_{b}, Y_{b}\right)$, worst position $\left(X_{w}, Y_{w}\right)$, the mean of objective function $\left(I E_{\text {mean }}\right)$, and the worst of objective function $\left(I E_{\max }\right)$.

(6) While $G \leq G_{\max }$ do

(7) $X_{i}=X_{0}+$ rand, $\quad Y_{i}=Y_{0}+$ rand

(8) $D_{i}=\sqrt{X_{i}^{2}+Y_{i}^{2}}, \quad S_{i}=1 / D_{i}, \quad S_{i}=\left[K_{p}, K_{i}\right]$

(9) Update each fruit fly's position using the following formulas:

$$
\begin{aligned}
& \text { If }\left(\mathrm{IE}_{i} \leq \mathrm{IE}_{\text {mean }}\right) \\
& \quad X_{i}=X-2 * X_{w} \\
& Y_{i}=Y-2 * Y_{w} \\
& \text { end } \\
& \text { If }\left(\mathrm{IE}_{\text {mean }}<\mathrm{IE}_{i}<\mathrm{IE}_{\max }\right) \\
& X_{i}=X+2 * X_{b} \\
& Y_{i}=Y+2 * Y_{b} \\
& \text { end } \\
& \text { If }\left(\mathrm{IE}_{i} \geq \mathrm{IE}_{\max }\right) \\
& \quad X_{i}=X+X_{w} \\
& \quad Y_{i}=Y+Y_{w} \\
& \text { end }
\end{aligned}
$$

(10) Update $X_{b}, Y_{b}, \mathrm{IE}_{b}$

(11) End

Algorithm 1

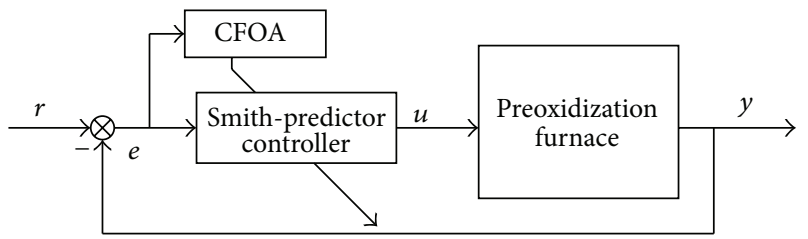

FIgURE 7: Smith-predictor control system combined with the CFOA.

The Smith-predictor controller can eliminate the effect of time delay, which is extensively used in process industry. So, the Smith-predictor controller is used in preoxidization furnace. Parameter search interval $\left[\theta_{\min }, \theta_{\max }\right]=[0,300]$, the population size is 20 , and the number of iterations (generations) is 50. Search for a set of optimal PI control gains for a class of preoxidization furnaces of (12) via the CFOA such that the objective function IE of (10) is minimized. The complete steps for designing the CFOA-based Smithpredictor controller system are summarized in Algorithm 1.

4.3. Simulation Results. Usually, we use the same transfer function model for all of the 10 zones. So, taking Zone 1 as an example, we can obtain satisfactory control performance of system (12) by the Smith-predictor controller, as shown in Figure 8. We compare the control effectiveness of the FOA, the PSO, and the CFOA to obtain the optimal PI gains. Figure 9 is the contrast effectiveness of the influence on

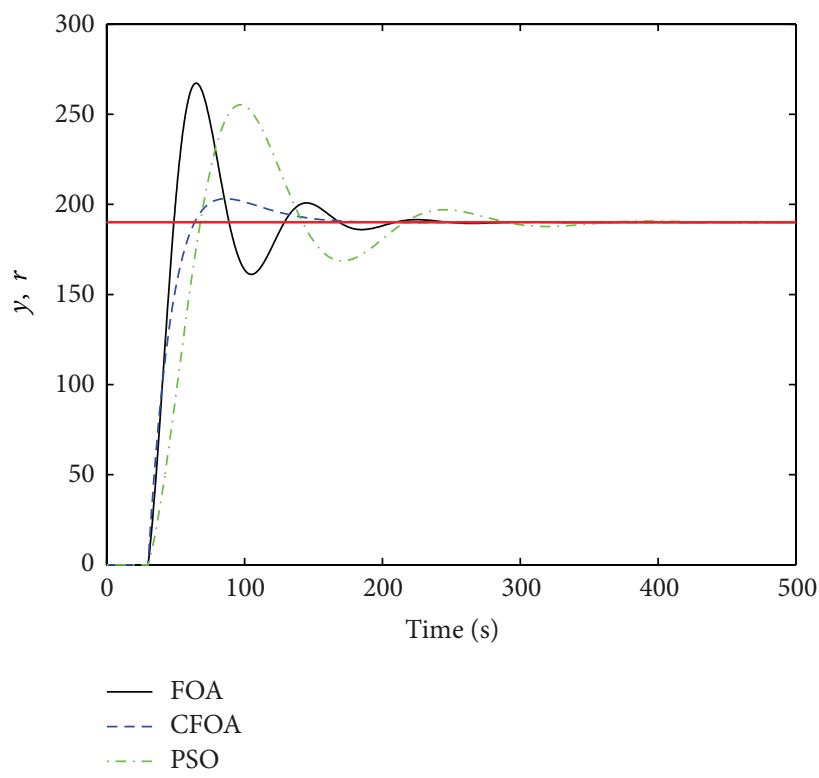

FIGURE 8: Comparison of control effectiveness among the FOA, the $\mathrm{PSO}$, and the CFOA.

Zone 1 temperature of preoxidization furnace with the level changing.

We compare the control effectiveness of the CFOA with that of the FOA and the PSO optimal control schemes. 
TABLE 5: Treatment temperature and time of PAN fibers in each furnace zone.

\begin{tabular}{lcccccccccc}
\hline Temperature zone & 1 & 2 & 3 & 4 & 5 & 6 & 7 & 8 & 9 \\
\hline Temperature $\left({ }^{\circ} \mathrm{C}\right)$ & 190 & 200 & 210 & 220 & 230 & 240 & 250 & 260 & 260 & 270 \\
Time $(\min )$ & 4.12 & 4.12 & 4.04 & 4.04 & 3.74 & 3.74 & 3.68 & 3.68 & 3.68 & 3.68 \\
\hline
\end{tabular}

TABLE 6: Control parameters.

\begin{tabular}{lcc}
\hline Control algorithm & $K_{p}$ & $K_{i}$ \\
\hline PSO & 0.0162 & 0.0024 \\
FOA & 0.04 & 0.008 \\
CFOA & 0.0786 & 0.0026 \\
\hline
\end{tabular}

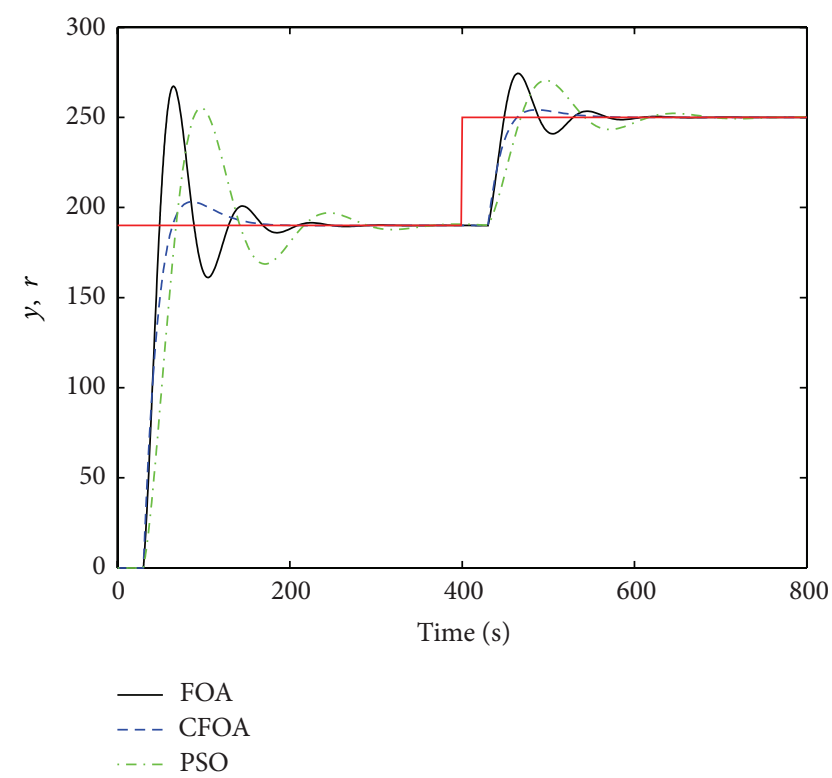

Figure 9: Responses with temperature set point changing.

Figure 8 shows the performance of the three types of optimization algorithms; the simulation results show that the CFOA-based Smith-predictor controller is very sensitive toward the set points. Figure 9 is the contrast effectiveness of the influence on the preoxidization furnace temperature with the sudden changing. The goal is to test whether the optimization control algorithm has the ability to quickly return to its normal working status after the sudden changing. We change the set point of the temperature at the 400th sampling period. From Figure 9, we can see that the Smithpredictor controller is based on the CFOA to optimize PI gains, and we get the system response curve with faster rise time, small overshoot, reduced settling time. The detailed parameters are as shown in Table 6.

\section{Conclusions}

In this paper, an improved CFOA has been proposed and its performance was compared with the standard version of the FOA and the PSO. In experimental functions, we use the same maximum iteration number and the population number for all problems. The reason is that we assume the algorithms of other methods do not know much about the recommended values of these parameters for their problems to be optimized. The results from a set of numerical benchmark functions show that the CFOA outperforms the FOA in most of the experiments. Meanwhile, the CFOA is applied to optimize the controller for preoxidation furnaces in carbon fibers production. Simulation results demonstrate the CFOA can achieve the optimal PI gains of the Smith-predictor controller and thus overcome the shortcomings of poor adaptability of the FOA.

In the future, we will further improve the CFOA and hope that more researchers can participate in the test and promotion.

\section{Conflict of Interests}

The authors declare that there is no conflict of interests regarding the publication of this paper.

\section{Acknowledgments}

This work was supported in part by the Key Project of the National Nature Science Foundation of China (no. 61134009), the National Nature Science Foundation of China (nos. 61473077, 61473078), Cooperative Research Funds of the National Natural Science Funds Overseas and Hong Kong and Macao scholars (no. 61428302), Program for Changjiang Scholars from the Ministry of Education, Specialized Research Fund for Shanghai Leading Talents, Project of the Shanghai Committee of Science and Technology (nos. 13JC1407500, 11JC1400200), and Innovation Program of Shanghai Municipal Education Commission (no. 14ZZ067).

\section{References}

[1] Y. Chtioui, D. Bertrand, and D. Barba, "Feature selection by a genetic algorithm. Application to seed discrimination by artificial vision," Journal of the Science of Food and Agriculture, vol. 76, no. 1, pp. 77-86, 1998.

[2] K. S. Tang, K. F. Man, S. Kwong, and Q. He, "Genetic algorithms and their applications," IEEE Signal Processing Magazine, vol. 13, no. 6, pp. 22-37, 1996.

[3] J. Kennedy and R. Eberhart, "Particle swarm optimization," in Proceedings of the IEEE International Conference on Neural Networks, vol. 4, pp. 1942-1948, December 1995.

[4] L. Gao and A. Hailu, "Comprehensive learning particle swarm optimizer for constrained mixed-variable optimization problems," International Journal of Computational Intelligence Systems, vol. 3, no. 6, pp. 832-842, 2010. 
[5] Y.-F. Hu, Y.-S. Ding, K.-R. Hao, H. Han, and L.-H. Ren, "An immune orthogonal learning particle swarm optimisation algorithm for routing recovery of wireless sensor networks with mobile sink," International Journal of Systems Science, vol. 45, no. 3, pp. 337-350, 2014.

[6] D. Karaboga and B. Basturk, "A powerful and efficient algorithm for numerical function optimization: artificial bee colony (ABC) algorithm," Journal of Global Optimization, vol. 39, no. 3, pp. 459-471, 2007.

[7] Z.-H. Hu, "A container multimodal transportation scheduling approach based on immune affinity model for emergency relief," Expert Systems with Applications, vol. 38, no. 3, pp. 2632-2639, 2011.

[8] N. Xu, Y.-S. Ding, and K.-R. Hao, "Immunological mechanism inspired iterative learning control," Neurocomputing, vol. 145, no. 5, pp. 392-401, 2014.

[9] J. J. Chen, Y.-S. Ding, Y.-C. Jin, and K.-R. Hao, "A synergetic immune clonal selection algorithm based multi-objective optimization method for carbon fiber drawing process," Fibers and Polymers, vol. 14, no. 10, pp. 1722-1730, 2013.

[10] H. Han, Y.-S. Ding, K.-R. Hao, and X. Liang, "An evolutionary particle filter with the immune genetic algorithm for intelligent video target tracking," Computers and Mathematics with Applications, vol. 62, no. 7, pp. 2685-2695, 2011.

[11] M. Lopez-Ibanez and T. Stutzle, "The automatic design of multiobjective ant colony optimization algorithms," IEEE Transactions on Evolutionary Computation, vol. 16, no. 6, pp. 861-875, 2012.

[12] W.-T. Pan, "A new fruit fly optimization algorithm: taking the financial distress model as an example," Knowledge-Based Systems, vol. 26, no. 2, pp. 69-74, 2012.

[13] H.-Z. Li, S. Guo, C.-J. Li, and J.-Q. Sun, "A hybrid annual power load forecasting model based on generalized regression neural network with fruit fly optimization algorithm," KnowledgeBased Systems, vol. 37, pp. 378-387, 2013.

[14] S.-M. Lin, "Analysis of service satisfaction in web auction logistics service using a combination of Fruit fly optimization algorithm and general regression neural network," Neural Computing and Applications, vol. 22, no. 3-4, pp. 783-791, 2013.

[15] W. Sheng and Y. Bao, "Fruit fly optimization algorithm based fractional order fuzzy-PID controller for electronic throttle," Nonlinear Dynamics, vol. 73, no. 1-2, pp. 611-619, 2013.

[16] C. S. Tu, C. T. Chang, K. K. Chen, and H. A. Lu, "A study on business performance with the combination of Z-score and FOAGRNN hybrid model," African Journal of Business Management, vol. 7, no. 26, pp. 7788-7798, 2012.

[17] H. Li, S. Guo, H. R. Zhao, C. B. Su, and B. Wang, "Annual electric load forecasting by a least squares support vector machine with a fruit fly optimization algorithm," Energies, vol. 5, no. 11, pp. 4430-4445, 2012.

[18] P.-W. Chen, W.-Y. Lin, T.-H. Huang, and W.-T. Pan, "Using fruit fly optimization algorithm optimized grey model neural network to perform satisfaction analysis for e-business service," Applied Mathematics and Information Sciences, vol. 7, no. 2, pp. 459-465, 2013.

[19] Y. Wang, T. Weise, J. Wang, B. Yuan, and Q. Tian, "Self-adaptive learning based particle swarm optimization," Information Sciences, vol. 181, no. 20, pp. 4515-4538, 2011.

[20] S. L. Sabat, L. Ali, and S. K. Udgata, "Integrated learning particle swarm optimizer for global optimization," Applied Soft Computing, vol. 11, no. 1, pp. 574-584, 2011.
[21] D. Karaboga and B. Basturk, "On the performance of artificial bee colony (ABC) algorithm," Applied Soft Computing Journal, vol. 8, no. 1, pp. 687-697, 2008.

[22] D. Karaboga and B. Akay, "A comparative study of artificial Bee colony algorithm," Applied Mathematics and Computation, vol. 214, no. 1, pp. 108-132, 2009.

[23] N. Yusof and A. F. Ismail, "Post spinning and pyrolysis processes of polyacrylonitrile (PAN)-based carbon fiber and activated carbon fiber: a review," Journal of Analytical and Applied Pyrolysis, vol. 93, pp. 1-13, 2012.

[24] S. Chand, "Carbon fibers for composites," Journal of Materials Science, vol. 35, no. 6, pp. 1303-1313, 2000.

[25] S. Ozbek and D. H. Isaac, "Strain-induced density changes in PAN-based carbon fibres," Carbon, vol. 38, no. 14, pp. 20072016, 2000.

[26] Z. Wangxi, L. Jie, and W. Gang, "Evolution of structure and properties of PAN precursors during their conversion to carbon fibers," Carbon, vol. 41, no. 14, pp. 2805-2812, 2003.

[27] M. Yu, C. Wang, Y. Bai, Y. Wang, Q. Wang, and H. Liu, “Combined effect of processing parameters on thermal stabilization of PAN fibers," Polymer Bulletin, vol. 57, no. 4, pp. 525-533, 2006.

[28] Y. P. Hou, T. Q. Sun, H. J. Wang, and D. Wu, "Influence of ozone on chemical reactions during the stabilization of polyacrylonitrile as a carbon fiber precursor," Journal of Applied Polymer Science, vol. 108, no. 6, pp. 3990-3996, 2008.

[29] Y. Xue, J. Liu, F. Lian, and J. Y. Liang, "Effect of the oxygeninduced modification of polyacrylonitrile fibers during thermal-oxidative stabilization on the radial microcrystalline structure of the resulting carbon fibers," Polymer Degradation and Stability, vol. 98, no. 11, pp. 2259-2267, 2013.

[30] K. A. Ahmed and J. Xiang, "Mechanisms of cellular communication through intercellular protein transfer," Journal of Cellular and Molecular Medicine, vol. 15, no. 7, pp. 1458-1473, 2011.

[31] B. Liu, L. Wang, Y. H. Jin, F. Tang, and D. X. Huang, "Improved particle swarm optimization combined with chaos," Chaos, Solitons \& Fractals, vol. 25, no. 5, pp. 1261-1271, 2005.

[32] D. Ortiz-Boyer, C. Hervás-Martínez, and N. García-Pedrajas, "A crossover operator for evolutionary algorithms based on population features," Journal of Artificial Intelligence Research, vol. 24, pp. 1-48, 2005.

[33] M. Jing, C. G. Wang, Y. X. Wang, B. Zhu, X.-P. Gao, and W.-N. Chen, "Effects of preoxidation and carbonization technologies on tensile strength of PAN-based carbon fiber," Journal of Applied Polymer Science, vol. 108, no. 2, pp. 1259-1264, 2008.

[34] M. S. A. Rahaman, A. F. Ismail, and A. Mustafa, "A review of heat treatment on polyacrylonitrile fiber," Polymer Degradation and Stability, vol. 92, no. 8, pp. 1421-1432, 2007.

[35] M. X. Ji, C. G. Wang, Y. J. Bai, M. Yu, and Y. Wang, "Structural evolution of polyacrylonitrile precursor fibers during preoxidation and carbonization," Polymer Bulletin, vol. 59, no. 4, pp. 527536, 2007. 


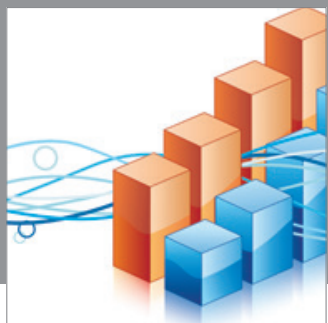

Advances in

Operations Research

mansans

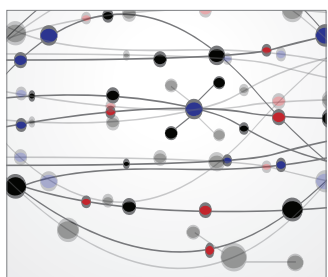

The Scientific World Journal
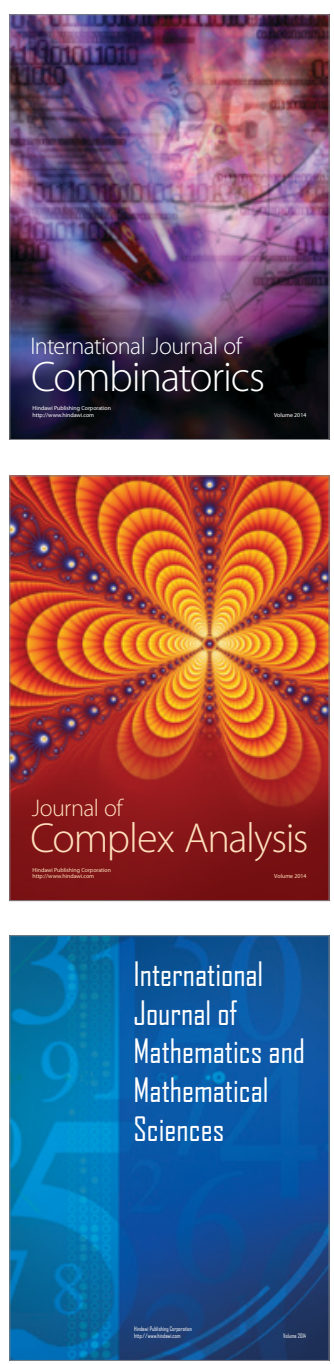
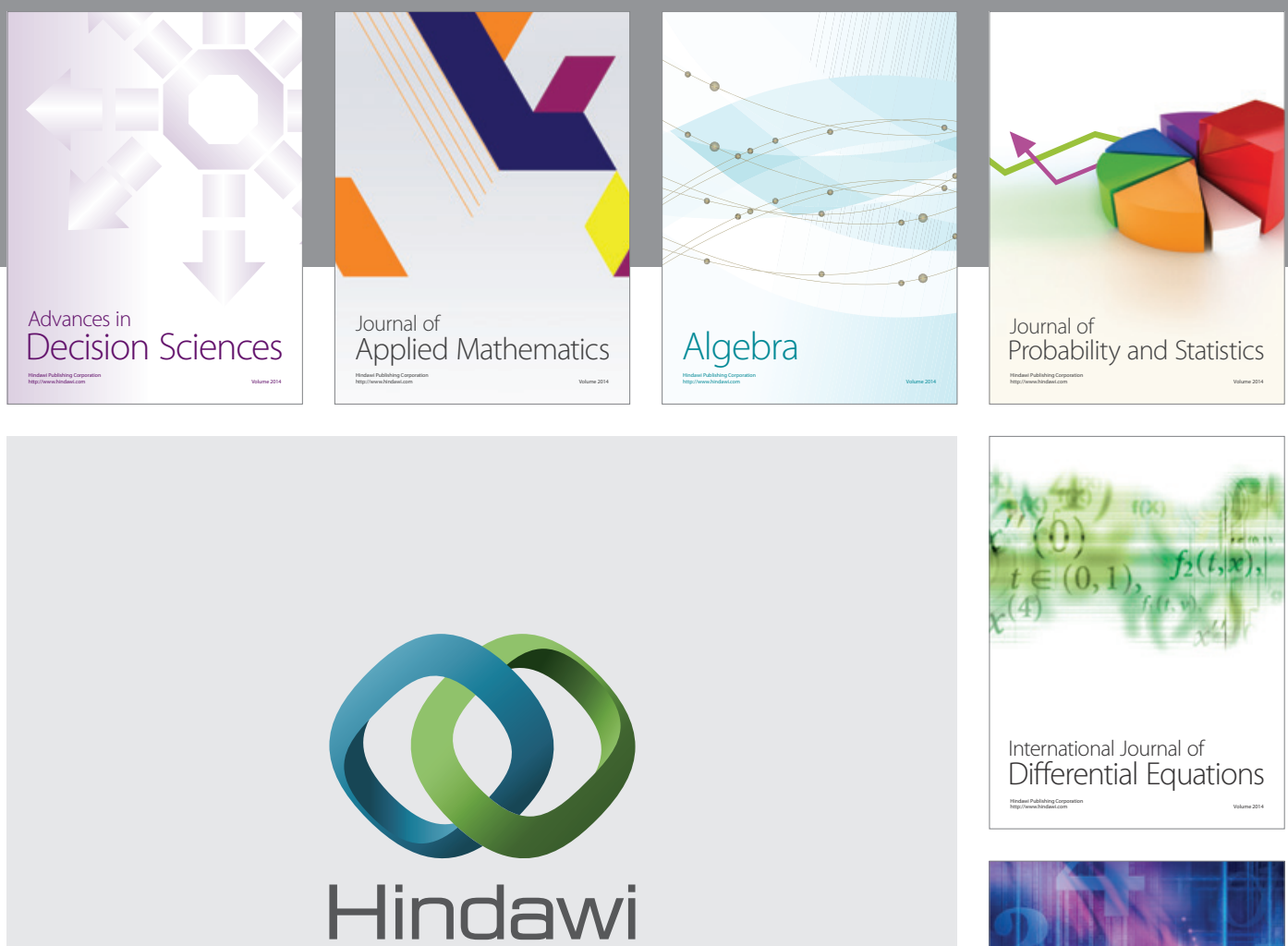

Submit your manuscripts at http://www.hindawi.com
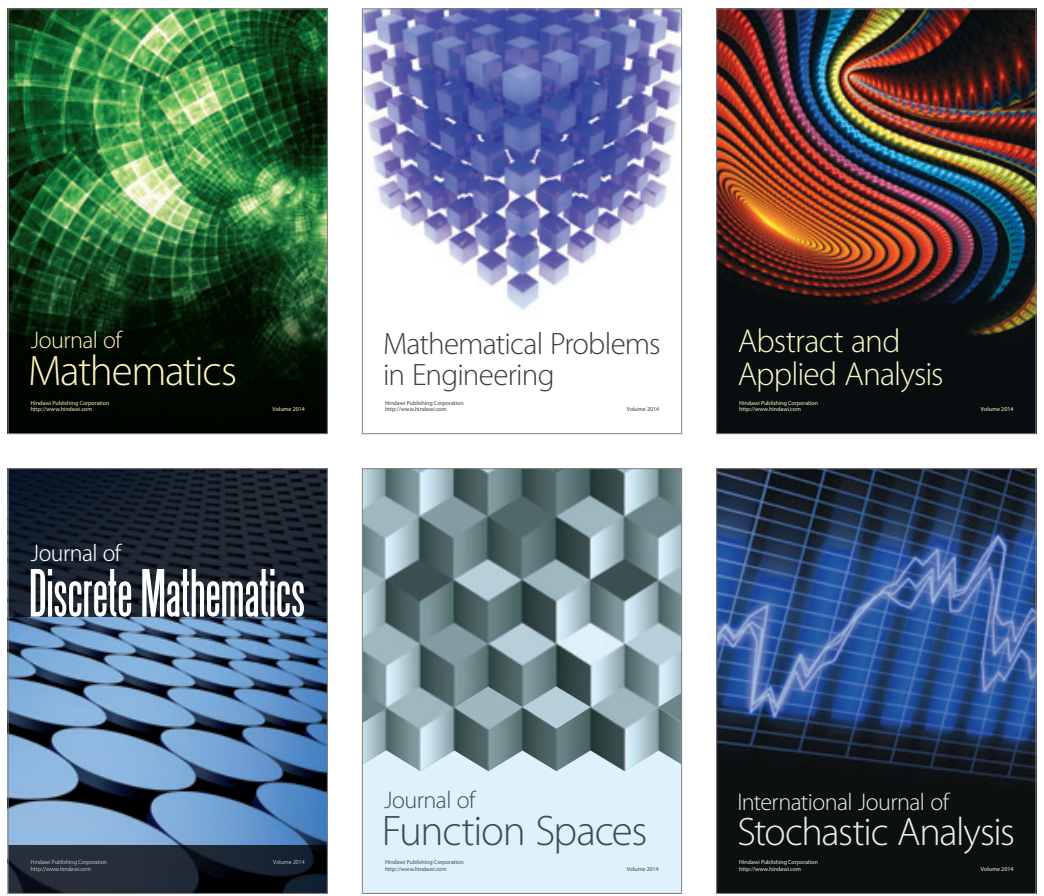

Journal of

Function Spaces

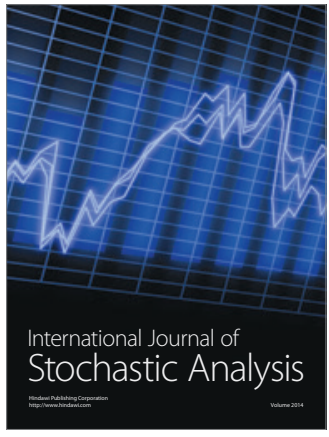

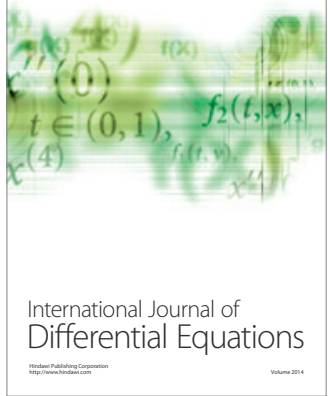
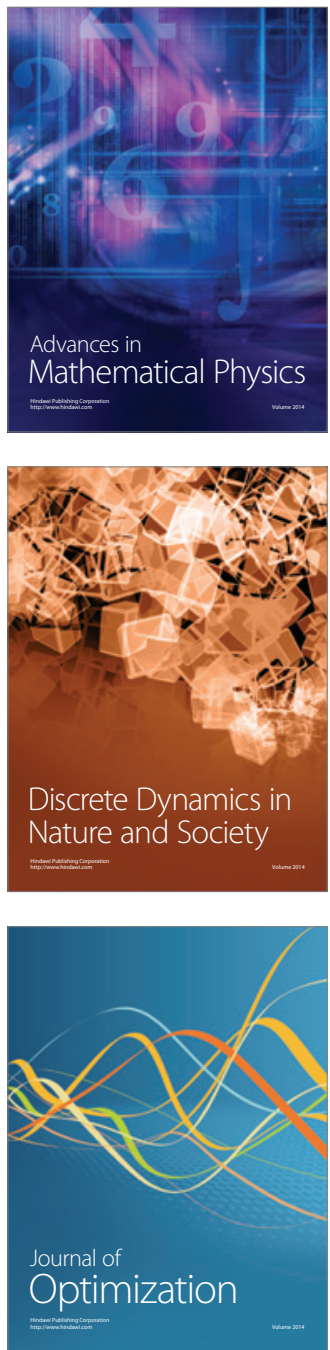